\title{
Osteosarcoma tumor microenvironment: the key for the successful development of biologically relevant 3D in vitro models
}

\author{
João Rodrigues ${ }^{1,2,3,4} \cdot$ Bruno Sarmento $^{1,2,5} \cdot$ Catarina Leite Pereira ${ }^{1,2}$
}

Received: 6 November 2021 / Revised: 9 January 2022 / Accepted: 9 January 2022 / Published online: 18 January 2022

(c) The Author(s), under exclusive licence to Springer Nature Switzerland AG 2022

\begin{abstract}
Osteosarcoma (OS) is the most common primary bone cancer in children and young adults. This type of cancer is characterized by a high mortality rate, especially for patients with resistant lung metastases. Given its low incidence, high genetic heterogeneity, the lack of effective targets, and poor availability of relevant in vitro and in vivo models to study the tumor progression and the metastatic cascade, the pathophysiology of OS is still poorly understood and the translation of novel drugs into the market has become stagnant. Due to the importance of the tumor microenvironment (TME) in the development of metastases and the growing interest in targeting TME-specific pathways for novel therapeutics in cancer, models that closely represent these interactions are crucial for a better understanding of cancer-related events. In OS research, most studies rely on oversimplified two-dimensional (2D) assays and complex animal models that do not faithfully recapitulate OS development and progression. In turn, three-dimensional (3D) models are able to mimic not only the physical 3D environment in which cancer cells grow but also involve interactions with the TME, including its extracellular matrix, and thus are promising tools for drug screening studies. In this review, the existing and innovative OS in vitro 3D models are highlighted, focusing on how the TME is crucial to develop effective platforms for OS tumor and metastasis modeling in a physiologically relevant context.
\end{abstract}

Keywords Osteosarcoma $\cdot$ Tumor microenvironment $\cdot$ Metastasis $\cdot 3 \mathrm{D}$ in vitro models $\cdot$ Microfluidics

Catarina Leite Pereira

catarina.pereira@i3s.up.pt

1 Instituto de Investigação E Inovação Em Saúde (i3S), University of Porto, Rua Alfredo Allen, 208, 4200-135 Porto, Portugal

2 Instituto de Engenharia Biomédica (INEB), University of Porto, Rua Alfredo Allen, 208, 4200-135 Porto, Portugal

3 Instituto Ciências Biomédicas Abel Salazar (ICBAS), University of Porto, Rua Jorge Viterbo 228, 4150-180 Porto, Portugal

4 Faculdade de Engenharia da Universidade Do Porto (FEUP), University of Porto, Rua Dr. Roberto Frias, 4200-465 Porto, Portugal

5 CESPU, Instituto de Investigação E Formação Avançada Em Ciências E Tecnologias da Saúde, Rua Central da Gandra 1317, 4585-116 Gandra, Portugal

\section{Introduction}

Sarcomas are a group of solid neoplasms that originate from mesenchymal cells. These types of cancer are far less common than epithelial-derived carcinomas. In particular, osteosarcoma (OS) is a high-grade primary skeletal malignancy characterized by immature osteoid matrix deposition from cancer cells [1]. It has an annual incidence rate of around 3.1 cases per million people in the USA and 0.3 cases per 100,000 people in Europe, accounting for less than $1 \%$ of all newly diagnosed cancer in adults [2]. OS is the most common primary bone malignancy in children and the third most common cancer in adolescence, having a peak incidence between the ages of 10 and 14 years and in individuals over 60 years old [2]. OS develops mainly at the metaphysis or lower extremity of long bones, possibly related to puberty and bone growth that occurs around this age [3]. Risk factors associated with the disease include rapid bone turnover, ionizing radiation to the bone, pre-existing bone diseases (Paget's disease), and heritable genetic syndromes that result in predisposition to OS [3]. Nevertheless, OS appears 
sporadically in about $95 \%$ of cases [2]. For the past 40 years, OS treatment has involved neoadjuvant or induction combinatory post-operative chemotherapy. The most commonly used drugs include methotrexate, adriamycin (doxorubicin), and platinol (cisplatin) - the so-called MAP therapy that can be combined with ifosfamide $[1,4]$. OS survival rate has increased constantly until the late 1980s with a combination of improved surgical techniques (conservative surgery vs. amputation) and the introduction of chemotherapy [1]. Nonetheless, neither tumor resection surgery nor chemotherapy can control the metastatic spread of OS. Moreover, OS is usually radio-resistant and, in $90 \%$ of cases, OS metastasizes to the lung, leading to an extremely low 5-year survival rate $(<20 \%)$ [5]. The low OS prevalence coupled with high tumor heterogeneity between patients and resistance to anti-cancer drugs has greatly hampered the development of effective therapies due to difficulty in finding targetable events. Another hurdle is the complex tumor microenvironment (TME) that is composed of bone cells, immune cells, stromal cells (mesenchymal stem/stromal cells (MSCs) and fibroblasts), vascular cells (endothelial cells and pericytes), and a dense mineralized extracellular matrix (ECM) [6]. Recently, the OS TME has been studied as a target for novel therapies $[6,7]$. However, these studies are associated with controversial results and failures in the improvement of the efficacy of treatments, which remains a considerable challenge to overcome in this research field. One possible reason for this is the lack of relevant in vitro platforms that include the TME and allow to study OS progression and its metastatic process.

In OS-related research, two-dimensional (2D) models with immortalized cell lines have been substantially explored for experimental and drug screening studies. Great knowledge has been acquired from these cell culture assays; however, they fail to recapitulate the dynamic environment in which cancer cells grow, including proper cell-cell and cell-ECM interactions that influence cancer progression and drug resistance [8]. Moreover, considering the TME as a relevant disease defining factor brings the value of contemplating biomechanical and physical cues and not only the genetic changes that promote tumor cell proliferation [9]. The introduction of novel three-dimensional (3D) models has changed our ability to investigate cancer in vitro, bridging the gap between oversimplified 2D assays and overly complex animal models that often do not represent human-specific events. 3D models offer multiple features that faithfully mimic the 3D architecture of solid tumors and also their interactions with the surrounding TME, including (i) the ECM as an important player in cancer pathogenesis; (ii) the possibility to culture cells under dynamic conditions, including vasculature-mimicking systems; (iii) and increased controllability regarding specific cell responses (e.g., ECM stiffness, oxygen/metabolic levels, interpatient heterogeneity), allowing to undercover cancerrelated events under a relevant microenvironment $[8,10]$. Numerous scaffold-based models have been developed to mimic the ECM in vitro [11]. Biomaterials ranging from Matrigel ${ }^{\circledR}$ (reconstituted basement membrane of murine Engelbreth-Holm-Swarm sarcoma), collagen, or alginate to synthetic alternatives such as poly(lactic acid) (PLA) and poly(ethylene glycol) (PEG) or even decellularized matrices have been thoroughly explored to properly culture cells within a biomimetic environment [12-14]. Other strategies employing tumor spheroids and organoids provide a more complex approach emulating the interactions between multiple cell types and drug penetration profiles while preserving specific tumor features, which is especially important for drug screening studies [15, 16]. Emerging technologies such as 3D bioprinting and microfluidics represent a step forward in cancer modeling in vitro, allowing the creation of complex multicellular systems for high-throughput drug screening with a high level of controllability and physiological relevance $[17,18]$.

This review presents a brief overview of bone homeostasis, followed by a description of how the bone microenvironment is transformed in OS. Thereafter, the TME impact in lung metastasis formation is discussed as well as how it is possible to target the metastatic cascade and the TME to improve OS treatments. Finally, the available OS 3D in vitro models are presented, focusing on how it is possible to improve them toward the establishment of more relevant culture systems for modeling OS and its metastatic spread in vitro.

\section{Bone homeostasis vs. osteosarcoma pathophysiology}

The bone is a highly plastic tissue that constantly changes, growing and remodeling up until the early stages of adulthood. The three main cell types that form the bone tissue include osteoblasts, osteocytes, and osteoclasts. These cells interact with each other and with the surrounding environment to modulate and maintain bone homeostasis. When stimulated to promote bone formation, osteoblasts can inhibit the activity of osteoclasts. This balance between osteoblast and osteoclast activity is essential for bone homeostasis and the constant renewal of old bone and its replacement with newly synthesized mineralized bone matrix (Fig. 1a) [19]. Osteoblasts have parathyroid hormone (PTH) receptors that when bound to PTH lead to the expression of receptor activator of the nuclear factor- $\mathrm{\kappa B}$ (NF- $\mathrm{\kappa B}$ ) ligand (RANKL). This ligand binds to its receptor RANK on hematopoietic osteoclast precursors, promoting osteoclast differentiation. Conversely, osteoprotegerin (OPG) produced by osteoblasts and stromal cells is a potent inhibitor of osteoclast 


\section{a. Bone homeostasis}

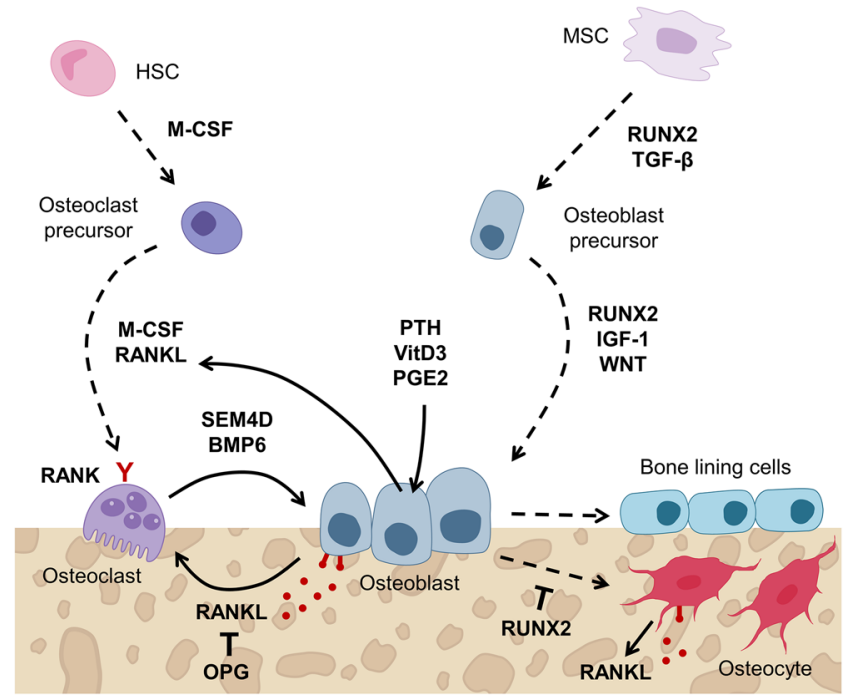

Fig. 1 Bone homeostasis vs. osteosarcoma-related bone remodeling. a Bone homeostasis is a complex process tightly regulated by the RANKL/RANK/OPG signaling pathway. RANKL is secreted by osteoblasts and osteocytes stimulated by PTH, vitamin D3, and prostaglandin E2. RANKL binds to the RANK receptor in the membrane of preosteoclasts differentiated from HSCs due to M-CSF activity, produced by immune cells and osteoblasts. Mature osteoclasts promote bone resorption, which is inhibited by OPG that binds to RANKL, blocking RANK signaling. b In OS, bone remodeling is induced by tumor cells that create a vicious cycle to promote cancer cell survival and proliferation. Tumor cells secrete RANKL,

differentiation, inhibiting the RANK/RANKL interaction [20]. PTH also controls OPG secretion to maintain bone homeostasis [20]. Osteoclast activity is also promoted by tumor necrosis factor (TNF)- $\alpha$ and macrophage colony-stimulating factor (M-CSF) produced by immune cells and osteoblasts, whereas transforming growth factor (TGF)- $\beta$ produced by macrophages can induce the recruitment of MSCs, which are osteoblast precursors, thus leading to osteoblast proliferation [21]. In addition, RANKL reverse signaling is also an important pathway regulating bone homeostasis, in which RANK secreted from extracellular vesicles (EVs) of maturing osteoclasts binds to osteoblastic RANKL, thus promoting bone formation [22].

OS oncogenesis and its metastatic spread are currently poorly understood. The molecular characterization of OS also remains incomplete mainly due to high intratumoral and intertumoral heterogeneity, the epigenetic complexity of the disease, and its low incidence. Although the origin of OS is still debated, evidence suggests that MSCs or MSCderived pre-osteoblasts may acquire genetic alterations that lead to OS formation and proliferation under the influence of specific TME signals [23]. Given that OSs have many characteristics of immature osteoblasts, more committed osteoblastic precursors could also be a part of OS origin.

\section{b. Tumor-induced bone remodeling}

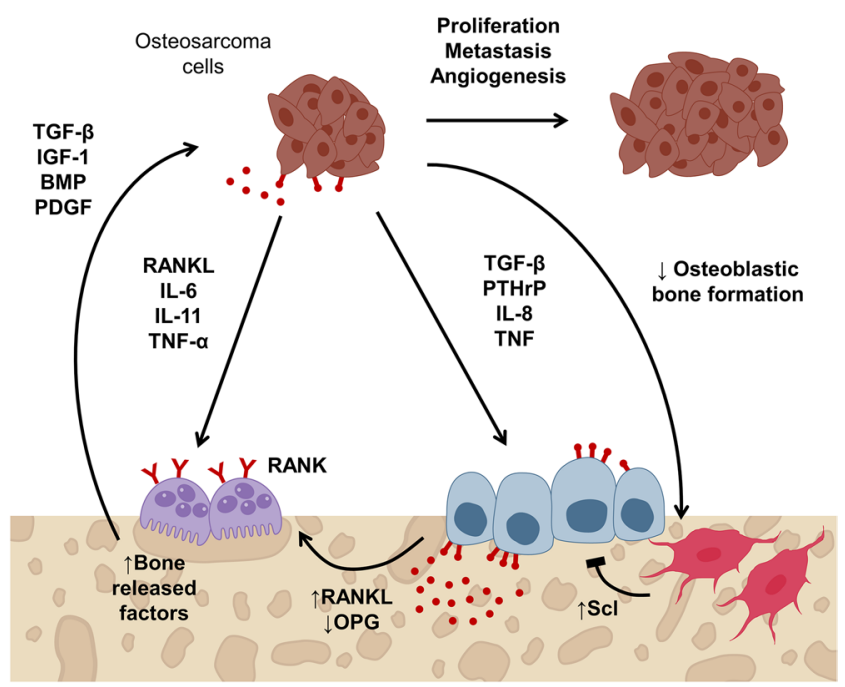

IL-6, IL-11, and TNF- $\alpha$ that stimulate osteoclastogenesis, leading to greater secretion of bone factors that promote tumor cell survival. Moreover, OS cells release factors, such as TGF- $\beta$, that promote the secretion of RANKL by osteoblasts and inhibit their activity, decreasing osteoblastic bone formation. Tumor cells also promote the secretion of sclerostin $(\mathrm{Scl})$ from osteocytes that inhibits osteoblast's activity. This creates a tumor-enhancing environment where the expression of OPG is generally decreased, while the expression of RANKL is normally enhanced. PTHrP, PTH-related protein, SEM4D, semaphorin-4D

Effectively, some data support OS originating from a more committed osteoblast pool of cells rather than MSCs [23]. Osteogenic differentiation is a tightly regulated process as a result of multiple signaling pathways (WNT and bone morphogenetic protein (BMP)), transcriptional regulators (TP53, RUNX2, ZEB1, and ZNF521), and cell cycle controllers (RB1) [24, 25]. Therefore, genetic alterations (such as germline mutations in TP53, RB1, RECQL4) may result in incompletely differentiated osteoblasts or osteoclasts that disrupt the balance between proliferation and differentiation of bone cells, thus leading to uncontrolled cell proliferation that may slowly expand to originate bone tumors [24]. Moreover, osteoclast activity is unregulated in OS, leading to excessive bone resorption (Fig. 1b). Tumor cells secrete RANKL, interleukin (IL)-6, IL-11, and TNF- $\alpha$, which stimulate osteoclast activity, thus leading to increased release of bone matrix entrapped factors (such as platelet-derived growth factor (PDGF), insulin-like growth factor (IGF)-1, and TGF- $\beta$ ) that promote cancer cell survival and proliferation [26].

The accumulation of these genetic alterations has been reported to generate a subpopulation of OS cancer stem cells (CSCs) able to self-renew and sustain tumor progression through interactions with the TME [27]. This cancer stem 
cell niche is also associated with drug-resistance events related to increased expression of drug efflux systems (ABC transporters and Aldefluor activity), altered DNA repair activity, epigenetic factors, and expression of anti-apoptotic proteins [28]. Moreover, conventional chemotherapy has been shown to induce the selection of stem-like cells in OS, specifically through the activation of the WNT/ $\beta$-catenin signaling pathway [28, 29]. Therefore, targeted therapies have been explored to tackle this issue, including inactivating the Hedgehog, Notch, and WNT signaling pathways [27, 30]. For instance, the early steps of metastasis, such as invasion and intravasation of tumor cells, are promoted by the activation of the WNT/ $\beta$-catenin pathway [31]. This signaling pathway induces the acquisition of stem cell properties by OS cells; promotes ECM remodeling, allowing tumor cell invasion; induces the expression of vascular endothelial growth factor (VEGF), leading to angiogenesis; and enhances the formation of an immune tolerant environment by enhancing pro-tumorigenic macrophage polarization and inhibiting the activity of cytotoxic T cells [31]. Inhibiting the WNT signaling pathways has been demonstrated to prevent OS metastasis in a human xenograft model on immunodeficient mice [32]. However, these signaling pathways are related to skeletal development in children, so it may be unsafe to inhibit them [3].

Other relevant pathways implicated in OS pathophysiology include phosphatidylinositol-3-kinase/protein kinase $\mathrm{B} / \mathrm{mammalian}$ target of rapamycin (PI3K/Akt/mTOR), RANKL/NF- $\kappa$ B, TGF- $\beta$, and IGF signaling pathways [3, 33]. All these signaling pathways have been explored to develop novel OS treatments. Unfortunately, disappointing results from recent clinical studies highlight the need for novel targets. For instance, the combination of sorafenib, a small molecular inhibitor of multiple tyrosine kinase receptors (RAF, KIT, VEGFR, PDGFR), and a rapamycin analog that inhibits the mTOR pathway showed promising results in preclinical studies but a recent clinical trial revealed only a $45 \%$ progression-free survival rate [34]. Therefore, there is a clear need for novel targets and more robust preclinical models to faithfully recapitulate OS progression both in vitro and in vivo in order to understand relevant cancer-TME interactions that lead to OS development and metastases.

\section{How can the tumor microenvironment influence metastasis?}

The metastatic spread of OS accounts for the poor survival rate associated with the disease. The metastatic cascade comprises multiple steps from cancer cell invasion of the surrounding tissue, intravasation into blood/lymphatic vessels, survival in circulation, extravasation into the secondary organ, and establishment of a secondary tumor in a distant site [35]. Since the lung is an efficient organ for filtration, OS cells preferentially metastasize to the lung due to mechanical restriction. The human alveolar capillaries have a smaller average diameter than OS cells that favors their entrapment within the lung tissue [36]. Another possible explanation is the development of a pre-metastatic niche (PMN). This concept encompasses the creation of a fertile environment in a secondary organ for the establishment and proliferation of metastases. The importance of the PMN in OS has been recently demonstrated in an orthotopic xenograft model [37]. OS cells were demonstrated to release TGF- $\beta$ expressing EVs that promoted the production of high levels of IL-6 from MSCs, thus stimulating the activation of intratumor STAT3 (cell proliferation-related transcription factor), which in turn led to tumor growth, enhanced invasion potential, and lung metastasis formation [37]. Additionally, another study revealed the activation of lung fibroblasts to a cancer-associated phenotype by OS cell-derived EVs [38]. This process was shown to be dependent on TGF- $\beta 1$ expression by OS EVs, highlighting how tumor cells can modulate the lung PMN to support the metastatic process [38, 39]. Furthermore, OS cells not only control the formation of a favorable distant PMN but also interact with other nonneoplastic cells, supporting the creation of a pro-metastatic TME in the bone.

\section{Cell crosstalk within the osteosarcoma tumor microenvironment}

The OS TME is a highly plastic and complex environment composed of multiple cell types (mainly bone, stromal, and vascular cells) immersed in a dense mineralized ECM that surrounds and communicates with cancer cells [6]. The crosstalk between all these cells facilitates immune evasion by tumor cells, angiogenesis, and cancer cell intravasation and dissemination, as well as the dysregulation of the bone remodeling process (Fig. 2). Moreover, these complex and dynamic interactions, together with high tumor heterogeneity and a lack of knowledge of its specific signaling pathways, thwart the development of effective therapies, especially for highly resistant metastatic OS tumors.

\section{Osteoblasts, osteoclasts, and cancer cells}

As mentioned, the molecular OPG/RANK/RANKL triad is crucial for the maintenance of the bone niche. Once OS develops in the bone, tumor cells secrete factors (PTHrelated protein, IL- 11 , TGF- $\beta 1$ ) that initiate osteoclastmediated bone reabsorption, a characteristic of most osteolytic bone tumors [40]. The RANK receptor and RANKL are normally expressed at the surface of osteoclasts and osteoblasts, respectively, but in the OS TME they can be expressed by tumor and immune cells. While osteoblasts 


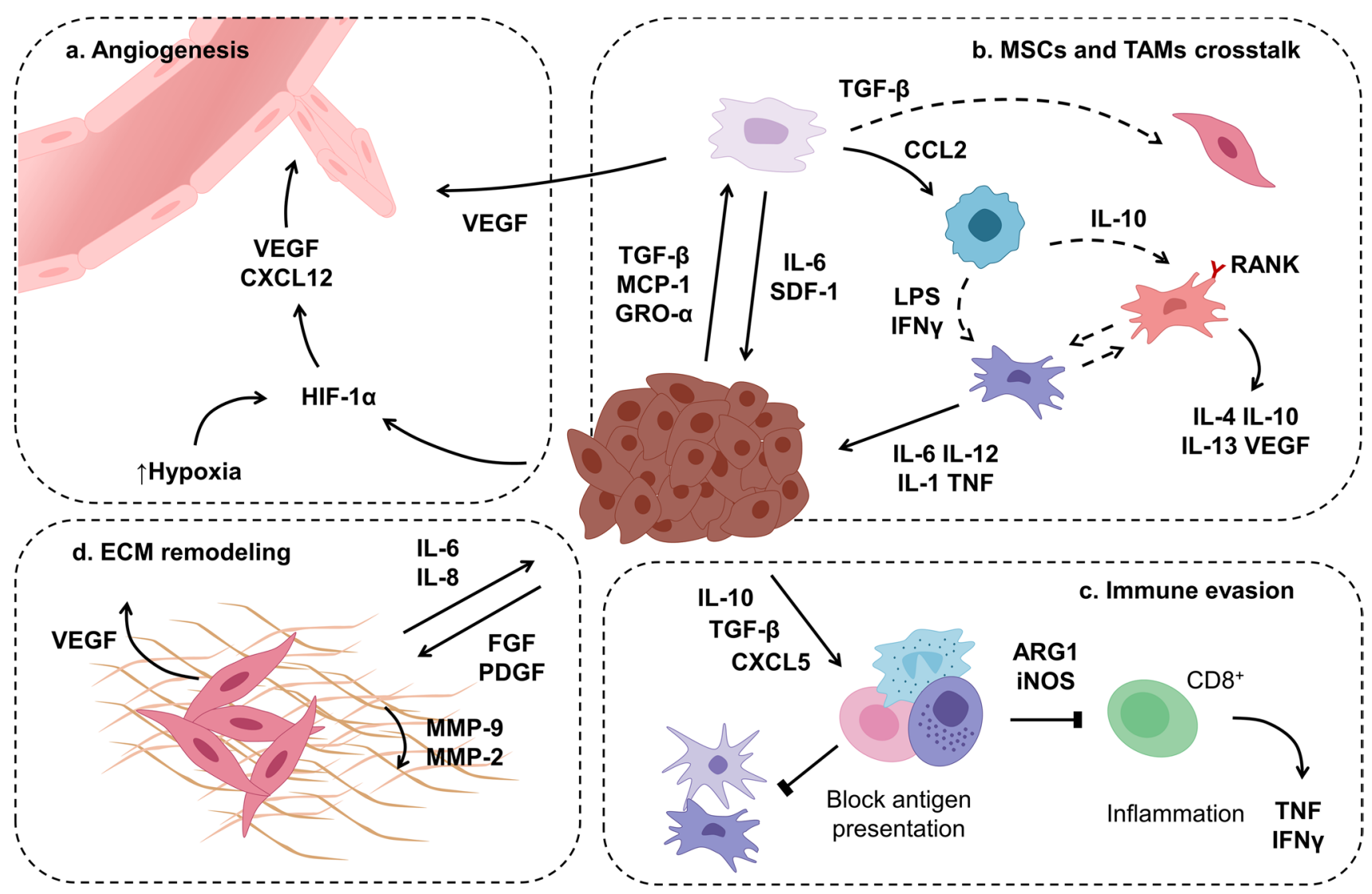

\begin{tabular}{|c|c|c|c|}
\hline $\begin{array}{l}\text { Osteosarcoma } \\
\text { cell }\end{array}$ & $\begin{array}{l}\text { Infiltrating } \\
\text { macrophage }\end{array}$ & Dendr & Neutrophils \\
\hline $\begin{array}{l}\text { Mesenchymal } \\
\text { stromal/stem cell }\end{array}$ & $\begin{array}{l}\text { Pro-inflammatory } \\
\text { (M1) macrophage }\end{array}$ & $\begin{array}{l}\text { Myeloid-derived } \\
\text { suppressor cell }\end{array}$ & $\begin{array}{l}\text { T regulatory } \\
\text { cell }\end{array}$ \\
\hline $\begin{array}{l}\text { Cancer-associated } \\
\text { fibroblast }\end{array}$ & $\begin{array}{l}\text { Pro-tumorigenic } \\
\text { (M2) macrophage }\end{array}$ & $\mathrm{T}$ cell & $\begin{array}{l}\text { Endothelial } \\
\text { cell }\end{array}$ \\
\hline
\end{tabular}

Fig. 2 Osteosarcoma tumor microenvironment interactions. (a) Tumor cells interact with endothelial cells and MSCs within a hypoxic environment, promoting the release of HIF-1 $\alpha$ VEGF, which induces angiogenesis. (b) Bone marrow-derived MSCs are attracted to the tumor site by CXCL12 and MCP-1 secreted by OS cells. Within the TME, MSCs are normally "educated" by tumor cells (through TNF signaling) to have pro-tumoral activity and can differentiate into cancer-associated fibroblasts. Circulating macrophages can infiltrate the TME and differentiate into pro-inflammatory M1-like macrophages that have anti-cancer activity, or anti-inflammatory M2-like macrophages that express RANK and promote tumor

and stromal cells typically secrete OPG, in the OS TME, there is a reduced expression of this molecule, leading to an uncontrollable proliferation of osteoclasts [41]. Therefore, high levels of RANKL/RANK in the TME are associated with worse OS outcomes. Moreover, the dysregulation of this cycle leads to increased release of protumorigenic factors trapped in the bone matrix [40]. For proliferation and angiogenesis. (c) OS cells promote immunosuppression through the activation of $\mathrm{T}$ regulatory cells, myeloid-derived suppressor cells, and neutrophils that suppress the activity of antigen-presenting cells and inhibit cytotoxic $\mathrm{CD} 8^{+} \mathrm{T}$ cells. (d) Cancerassociated fibroblasts are activated by FGF and PDGF released by cancer cells, and promote ECM remodeling, inducing the formation of a dense matrix structure, which in turn promotes the formation of a necrotic tumor core, leading to VEGF secretion and angiogenesis. ARG1, arginase 1, iNOS, inducible nitric oxide synthase, LPS, lipopolysaccharide, SDF-1, stromal cell-derived factor-1

instance, TGF- $\beta$ is known to enhance cell migration/invasion of tumor cells by the increased production of matrix metalloproteinases (MMPs) and promote osteoclasts' osteolytic activity by the enhanced expression of RANKL and IL-11 [42]. It also upregulates VEGF and PDGF, growth factors that have a key role in angiogenesis and tumor growth. Finally, it also exerts immunosuppressive effects 
by regulating immune cell proliferation and activity [42]. In the OS TME, the vicious cycle between osteoclasts and OS cells is also exacerbated by the release of EVs from tumor cells. In contrast to RANK-bearing EVs released from osteoclasts to promote bone formation, tumor cells can produce EVs with pro-osteoclastic factors. Indeed, EVs containing TGF- $\beta$, MMPs, CD-9, and RANKL were isolated from $143 \mathrm{~b}$ OS cells, thus highlighting a novel communication mechanism between tumor cells and the TME to induce bone destruction [43].

\section{Mesenchymal stem/stromal cells and fibroblasts}

MSCs are multipotent non-hematopoietic precursor cells found in many human tissues, primarily in the bone marrow. They can differentiate into multiple lineages (osteoblasts, chondroblasts, myoblasts, and adipocytes) while having the ability to self-renew [44]. MSCs migrate to the OS TME due to a strong tropism of monocyte chemoattractant protein (MCP)-1, growth-regulated oncogene (GRO)- $\alpha$, and TGF- $\beta 1$ [45]. Once in the TME, MSCs exhibit a cancerassociated fibroblast (CAF) phenotype and respond to tumor cells that express TNF- $\alpha$ in hypoxic conditions by increasing the expression of chemokines (CC motif chemokine ligand (CCL)5, CCL2, C-X-C motif chemokine ligand (CXCL)1, CXCL12, IL-6, IL-8), and VEGF that promote cancer cell survival, proliferation, invasion, and transendothelial migration [45-47]. These paracrine and autocrine factors released by MSCs affect various cell types in the TME, including immune, endothelial, and bone cells. For instance, CCL2 and CCL5 are related to monocyte and macrophage recruitment to the TME, while IL- 8 mediates the establishment of an immunosuppressive environment, and VEGF promotes endothelial cell proliferation and angiogenesis [44].

Furthermore, in OS, MSCs, CAFs, and osteoblasts secrete a dense ECM, characterized by tight collagen fibers [6]. Consequently, immune cells, such as T cells, have difficulty penetrating the ECM to reach the tumor site, hindering their anti-cancer activity and the efficacy of immunotherapies. MSCs also secrete EVs that allow communication with osteoblasts and OS cells, thus enhancing tumor cell survival and migration [48]. MSC-secreted EVs have been shown to carry OS supportive microRNAs and growth factors, as well as lactate and glutamate, that favor cancer cell proliferation and metabolism [6]. Conversely, OS cells inhibit osteogenic differentiation of MSCs, keeping them in an undifferentiated state through the TGF- $\beta / \mathrm{Smad} 2 / 3$ pathway, which promotes the secretion of pro-tumorigenic factors by MSCs [49]. This was also demonstrated in a different study where OS cells were shown to release TGF- $\beta$ rich EVs promoting the secretion of IL- 6 by MSCs [37], which in turns leads to enhanced OS migratory potential and stemness [50].

\section{Immune cell crosstalk}

The immune microenvironment of OS is not yet fully understood. However, some evidence suggests that it has a significant role in the metastatic spread of cancer cells [51]. The immune niche of OS is mainly composed of tumor-associated macrophages (TAMs). Other immune cells present include dendritic cells and lymphocytes [51]. Macrophages play a crucial role in the bone environment, influencing bone formation (through oncostatin secretion) and acting as osteoclast precursors in the presence of M-CSF and RANKL. Circulating monocytes are normally recruited to the OS TME by cancer cells (trough CCL2, CCL5, CSF1, VEGF, IL-34 secretion) and then may differentiate into macrophages. TAMs may also originate from tissue-resident macrophages and monocyte-related myeloid-derived suppressor cells (MDSCs) [52]. In the OS TME, TAMs possess high plasticity and can adopt multiple phenotypes according to the environmental signals received [53]. Generally, at either end of a broad polarization spectrum, classically activated or M1-polarized macrophages demonstrate anti-cancer activity as they promote the secretion of pro-inflammatory signals (IL-6, IL-12, IL-1, TNF), leading to an increase in immune cell activation. By contrast, alternatively activated or M2 macrophages are known as pro-tumorigenic cells that release anti-inflammatory signals (IL-10 and VEGF) related to immunosuppression, tumor progression, and angiogenesis [53]. In the context of OS, the high proportion of TAMs in the TME has been associated with reduced metastasis and improved survival, although both M1 and M2 macrophages are present [54]. Even though conflicting results have shown a lower survival rate related to higher TAM infiltration [55], studies have demonstrated the detection of more M1-like TAMs in non-metastatic patients, which is associated with the anti-tumor activity of these subtype of macrophages [56]. A higher number of M2-like TAMs suggest the formation of a more immunosuppressive microenvironment, with less proliferation of effector $\mathrm{T}$ cells and increased levels of immunosuppressive $\mathrm{TIM} 3^{+} \mathrm{PD}-1^{+}(\mathrm{T}$ cell immunoglobulin domain and mucin domain 3/programmed cell death protein 1 positive) T cells [51, 56]. Moreover, M2-polarized TAMs communicate with OS cells and MSCs to maintain the stem cell-like phenotype of cancer cells [57], and can release IL-1 $\beta$, a pro-inflammatory cytokine that activates the NF- $\mathrm{KB}$ and TNF signaling pathways, which are related to the enhanced tolerance of OS cells to chemotherapy [58].

The establishment of this complex immune niche within the OS TME is orchestrated by tumor cells, capable of controlling the recruitment and differentiation of immune cells, thus creating a tumor-favoring environment to potentiate cancer progression, metastasis, and drug resistance. Indeed, OS cells can dysregulate the balance between M1 and M2 macrophages, which stimulates a switch in the phenotype of 
TAMs from M1-like macrophages to pro-metastatic M2-like macrophages [51, 56]. Moreover, OS cells also control the response of T cells via the PD- 1 and programmed cell death protein-ligand 1 (PD-L1) recognition system, which inhibits the cytotoxicity activity of $\mathrm{T}$ cells and consequently leads to the formation of an immunosuppressive environment ideal for tumor growth $[55,59]$. In addition, the relatively low abundance of cytotoxic $\mathrm{CD} 8^{+} \mathrm{T}$ cells in the OS TME may suggest that OS tumors are poorly immunogenic, with a scarce infiltration and activity of lymphocytes [60]. This lower immune infiltrate level hinders the effectiveness of immune checkpoint inhibitors and the possibility to use targeted therapies that rely on immune cell activation.

\section{Vascular microenvironment}

The vascular niche not only regulates osteogenesis and hematopoiesis but also promotes tumor irrigation and survival by providing oxygen and nutrients to tumor cells. It also fosters the intravasation of cancer cells into blood vessels and their migration into a specific metastatic location [61]. The hypoxic and acidic bone microenvironment promotes the release of pro-angiogenic factors (hypoxiainducible factor (HIF) and VEGF) by tumor cells, leading to the formation of new blood vessels to irrigate the tumor site [61]. However, this process of neovascularization in OS remains poorly understood. It has been shown that neovascularization occurs mostly from pre-existing blood vessels, but there is also increasing evidence of the presence and activity of endothelial progenitor cells that can differentiate into mature endothelial cells after recruitment from the bone marrow [6, 62]. Furthermore, the formation of non-endothelial microchannels from OS cells, a process called vasculogenic mimicry, has also been reported and associated with a worse prognosis [63]. OS tumors are highly vascularized tissues, a fact that has been suggested as a poor prognostic factor. Moreover, it has been demonstrated that patients with low OS vascularization have a better survival outcome and a better response to chemotherapy [64]. By contrast, high expression of VEGF and VEGFR is associated with a lower survival rate and it is considered to be an effective biomarker of OS prognosis [65]. The activation of PDGFR by platelets also has been linked to increased OS cell growth and a poor prognosis [66].

\section{Extracellular matrix}

The main components of normal bone ECM are significantly altered in OS. ECM production is considerably increased, resulting in a stiffer stroma and a more aggressive cancer phenotype. Not only tumor cells but also activated fibroblasts enhance the deposition of collagen, fibronectin, laminin, and proteoglycans which leads to the formation of a stiffer and denser ECM [67]. Moreover, ECM remodeling is accomplished by the enzymatic degradation of ECM proteins by MMPs (MMP-2, MMP-9, and MMP-13 that function via the ERK-associated signaling pathways) and heparinase released by tumor cells. This allows cell invasion into adjacent tissues and intravasation into blood vessels [67]. ECM remodeling is also important in the lung, where OS cells usually extravasate to and establish metastases [68]. Recent studies have identified key ECM molecules responsible for OS development that may also be relevant prognostic biomarkers [67]. For instance, OS cells overexpress collagen triple helix repeat containing 1 (CTHRC1), which is related to metastasis development and a poor prognosis due to inhibition of collagen type I deposition [69]. Upregulation of $\alpha v \beta 3$ integrin and fibronectin has also been reported in OS, guiding tumor cell migration [70]. These specific ECM components could be a target of novel therapies to hamper the progression of OS, as it was demonstrated by a recent study [71], thus showing the importance of considering the $\mathrm{ECM}$ as a major player in OS progression.

\section{The tumor microenvironment and the metastatic cascade as novel targets for osteosarcoma therapy}

The current treatment for OS consists of surgical tumor resection in combination with chemotherapy, including doxorubicin, cisplatin, and methotrexate [72]. This therapy is usually effective for about $50 \%$ of patients. However, for patients with metastases or relapsed OS, the survival rate is only around $20 \%$, which emphasizes the urgent need for more effective treatments [5]. Therefore, multiple novel targets are being explored to improve the efficacy of OS therapies [7, 73] (Fig. 3). Given the importance of the RANKLRANK pathway in bone homeostasis and its dysregulation in OS, studies have investigated the potential of inhibiting this pathway to improve OS outcomes [41]. However, while whole-body deletion of RANKL proteins in a genetically engineered mouse model prevented OS development and metastases, RANK deletion in osteoblasts did not hinder OS progression [74]. Denosumab, a monoclonal antibody against RANKL approved for metastatic breast and prostate cancer, has also been explored for OS and it is currently in a phase II clinical trial [75]. Preclinical results have demonstrated its protective effect against bone loss [75, 76]; however, doxorubicin-inhibiting events have been reported [77]. Since the role of osteoclasts in OS tumorigenesis is still controversial and the RANKL reverse signaling pathway has not been studied in OS, more studies still need to be performed to explore this avenue for OS treatment.

In terms of targeting the bone microenvironment, ongoing studies include the utilization of bisphosphonates that prevent bone loss and have anti-angiogenic properties which support tumor regression [78]. Functionally, 


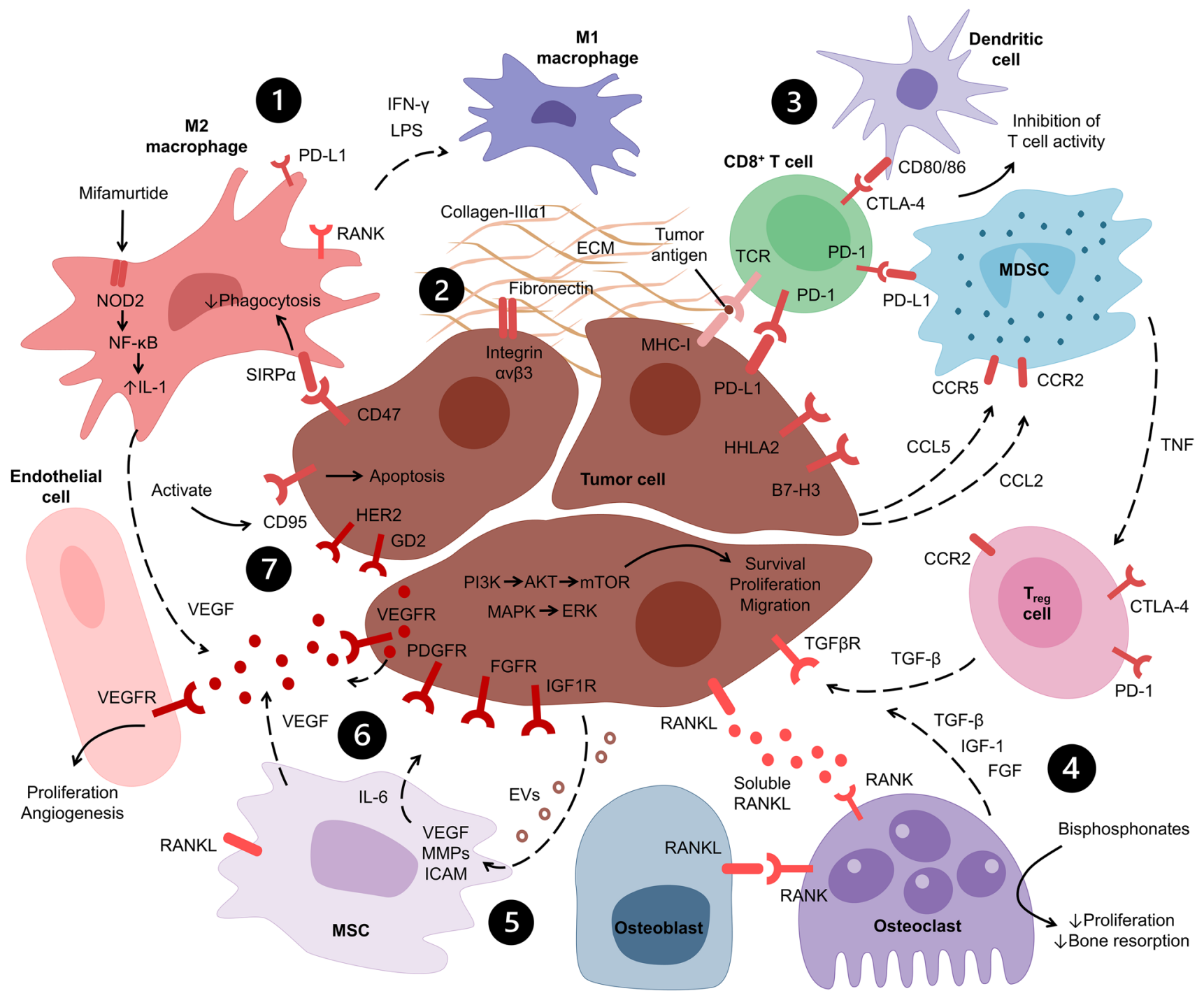

Fig. 3 Targeting the osteosarcoma tumor microenvironment. The strategies to target the OS TME to develop novel therapeutics include the following: (1) targeting TAMs by reprogramming M2-like macrophages into an anti-tumorigenic M1 phenotype, and promoting phagocytosis by inhibiting the SIRP $\alpha$ receptor; (2) targeting the ECM by inhibiting the tumorigenic activity of certain molecules (collagenIII $\alpha 1, \alpha v \beta 3$ integrin); (3) using monoclonal antibodies against immune checkpoint inhibitors (PD-1, PD-L1, CTLA-4, HHLA2, B7-H3) to promote the activity of cytotoxic T cells and inhibit the activity of MDSCs and T regulatory cells; (4) targeting osteoclast activity (with bisphosphonates), the RANKL/RANK signaling pathway (with monoclonal antibodies), and the activity of the TGF- $\beta$ receptor; (5) inhibiting the pro-tumorigenic activity of MSCs; (6) targeting multiple tyrosine kinase receptors (VEGFR, PDGFR, FGFR, IGF1R, HER2) that promote tumor cell survival and proliferation, as well as angiogenesis; (7) targeting other cell surface receptors overexpressed in OS cells (GD2) and promoting tumor cell apoptosis by enhancing the activity of the FAS receptor (CD95). LPS, lipopolysaccharide, MHC-I, major histocompatibility complex I, TCR, T cell receptor bisphosphonates interfere in osteoclast differentiation which hinders bone resorption and also have a direct role in OS cells' proliferation, leading to suppressed tumor growth and decreased expression of VEGFR [79]. The safe inclusion of bisphosphonates in adjuvant chemotherapy for OS has been reported; however, no clinical trials have demonstrated the effectiveness of this therapy [80].

Furthermore, the critical role of the immune system in cancer development and the complex crosstalk between tumor, immune, and bone cells has paved the way for the development of novel immunotherapies. Given the lack of specific markers of mesenchymal cells and the high heterogeneity of OS tumors, OS-specific antigens have been challenging to identify [3]. Nevertheless, one promising breakthrough has been immunoadjuvant therapy with mifamurtide (muramyl tripeptide phosphatidylethanolamine) [81]. The available MAP therapy is not specific for cancer cells and promotes the killing of effector $\mathrm{T}$ cells. Contrariwise, 
mifamurtide is a synthetic analog of a bacterial protein that can activate the immune system through the receptor NOD2 (nucleotide-binding oligomerization domain-containing protein 2) highly expressed in monocytes, maintaining a balance between pro-inflammatory M1 macrophages and pro-tumorigenic M2 macrophages [82]. Moreover, mifamurtide adjuvant therapy is related to increased serum levels of pro-inflammatory cytokines that hinder cancer progression. However, its use is controversial and only approved in the European Union [83]. Other promising immunotherapy molecules include type I interferons (IFNs), such as IFN- $\alpha$ which enhances OS cells' sensitivity to chemotherapy, as well as immune checkpoint inhibitors, such as anti-CTLA-4 (cytotoxic T lymphocyte-associated protein 4 ) and antiPD1/PDL1 [3]. However, recent clinical trial data has shown that single-agent checkpoint inhibitors therapies do not seem to contribute to tumor regression, which can be partially explained by the low neoantigen burden of most OS tumors $[84,85]$. Other alternatives include targeting the immunecheckpoint inhibitors HHLA2 and B7-H3 (CD276), as well as targeting the disialoganglioside GD2 with a monoclonal antibody in combination with granulocyte-M-CSF (GMCSF) to stimulate the anti-cancer activity of macrophages [7].

Furthermore, multiple studies and clinical trials are being performed to target receptor tyrosine kinases or their ligands overexpressed in the OS TME. Explored targets include VEGF, IGF-1, PDGF, HER2, and MET receptor tyrosine kinases [7, 86]. Unfortunately, the clinical trial results do not seem promising. Single targeting VEGF with the monoclonal antibody bevacizumab to inhibit angiogenesis has demonstrated low efficacy in improving OS outcomes [87]. Moreover, inhibiting IGF-1R has also shown disappointing results in phase II trials with patients with recurrent OS [88]. The most promising strategy has been targeting multiple tyrosine kinase receptors at the same time or combining specific targeting approaches with chemotherapeutic agents. For instance, cabozantinib can simultaneously inhibit VEGFR, PDGFR, MET, KIT, RET, and AXL receptor tyrosine kinases [86]. In addition, its efficacy has been demonstrated in phase II clinical trials, where a progression-free survival of 6.2 months was reached, the longer achieved for all similar treatments tested to date [89].

Lung colonization by cancer cells is associated with multiple metabolic adaptations that could also be possible targets for OS therapy. Notably, a recent epigenetic study has demonstrated considerable differences in enhancer activity between primary and metastatic OS [90]. This variation was also preponderant between metastatic and non-metastatic OS cell lines. The same study also highlighted that the expression of the variant regions is not random and may be positively selected to permit lung colonization by OS cells. One of the genes regulated by these regions-factor
3 (a gene that activates blood clotting)—showed particular importance for metastasis. Moreover, the knockdown of AP-1 transcription factors that occupy these variant regions inhibited cell outgrowth in the lung, thus underlining that these genomic regions have possible targets for OS therapy [90]. Another study highlighted the elimination of cancer cells through the activation of a cell death pathway related to the expression of the FAS receptor (CD95) [91]. Therefore, only FAS-negative OS cells were able to colonize the lung environment. Other targetable metabolic sensitivities associated with OS metastasis include the upregulation of glycoprotein 78, protein kinase C, IL-6, and CXCL8 activity, as well as altered glutathione metabolism [36]. For instance, a recent study has shown that the aberrant expression of $\Delta$ Np63 responds to signals from lung epithelial cells [92]. Xenografts, syngeneic mouse models, and canine models were employed in this study, demonstrating higher levels of IL-6 and CXCL8 produced by cancer cells linked to upregulation of $\Delta \mathrm{Np} 63$. Moreover, a specific combination therapy was able to inhibit the activity of these molecules, leading to inhibition of metastasis formation [92].

Given that most OS patients already appear to have lung metastases at the diagnosis stage, some argue that inhibiting metastatic progression should be the most biologically relevant measure to evaluate the efficacy of novel drugs [93]. However, to boost the translation of therapeutic approaches to the clinic, it is still necessary to improve our understanding of the OS metastatic cascade. For that, the interactions between OS cells and the lung microenvironment must be further explored, as well as the influence of the TME. Finally, improving the available cell culture and in vivo models should also strengthen our ability to faithfully recapitulate the metastatic progression of OS and effectively test and find novel OS targets and treatments.

\section{Current landscape of osteosarcoma 3D in vitro models}

In OS-related research, the development of novel preclinical in vitro models remains a challenge, due to the complexity and heterogeneity of OS, which is proven by the lack of relevant in vitro assays to study OS. Most of the available culture models are too simple and do not entirely mimic the TME and the pathophysiology of OS. Consequently, animal models continue to be one of the most used tools for OS studies. However, they are usually expensive, difficult to work with, too complex, and do not faithfully emulate cancer progression, which thwarts the translation of novel drugs into the market [7]. Indeed, more than $90 \%$ of novel cancer drugs/therapies do not reach the clinic, which can be partly explained by the poor reliability of our in vitro and in vivo models [94]. Thus, it is of particular importance 
to understand how we can improve the current in vitro models to properly investigate the OS metastatic cascade. This section focuses on the available experimental models to study OS, centered on 3D scaffold-based models, spheroids, organoids, and tumor-on-a-chip platforms (Table 1). The strengths and limitations of each model are discussed as well as how it is possible to improve them to further mimic the TME and allow for suitable drug screening studies.

\section{Scaffold-based models}

Scaffold-based assays provide a simple matrix for tumor cell seeding. They are defined as biomimetic environments forming a porous ceramic or polymeric structure that allows to emulate the natural environment in which cells grow [12, 115]. More sophisticated models may include sponges, hydrogels, decellularized matrices, or a combination of materials to originate, for instance, bio-responsive hydrogels to mimic the ECM. The bone tissue has been extensively explored for tissue engineering applications and for investigating cancer metastasis to the bone $[116,117]$. This has paved the way for the development of multiple strategies to mimic the bone microenvironment in vitro that stand relevant for further exploitation, namely, to create innovative platforms for OS modeling.

The bone microenvironment is a complex biomechanical system composed of multiple cell types dispersed in a dense and porous matrix. The bone matrix is composed of an inorganic phase $(65 \%)$ of mostly hydroxyapatite (HA) nanocrystals, an organic phase (25\%) of primarily type I collagen, and water (10\%) [19]. The HA nanocrystals present in the bone structure promote toughness and strength, while

Table 1 Examples of available osteosarcoma 3D models

\begin{tabular}{|c|c|c|c|c|c|}
\hline 3D model & Cell types & Fabrication technique & Scaffold material & Drug screening & Refs \\
\hline \multirow[t]{9}{*}{ Spheroids } & MG63 & Hanging drop & - & VO-chrysin & [95] \\
\hline & MG63, U2OS, 143b & ULA plates & - & Anti-miR-355, cisplatin & [96] \\
\hline & HOSS1 & ULA plates & - & $\begin{array}{l}\text { Doxorubicin, gemcitabine, } \\
\text { docetaxel, X-ray }\end{array}$ & [97] \\
\hline & MG63, 143b, LM7 & PHEMA coated plates & - & $\begin{array}{l}\text { Doxorubicin, cisplatin, } \\
\text { methotrexate }\end{array}$ & [98] \\
\hline & $\mathrm{SaOS}-2$ & $\begin{array}{l}\text { Hanging drop technique in } \\
\text { microfluidic chips }\end{array}$ & - & Doxorubicin & [99] \\
\hline & MG63 & $\begin{array}{l}\text { Microfluidic chips with non- } \\
\text { adherent surfaces }\end{array}$ & - & - & [100] \\
\hline & $\mathrm{SaOS}-2 / \mathrm{MSCs}$ & $\begin{array}{l}\text { Agarose microwells of 3D } \\
\text { printed molds }\end{array}$ & - & Doxorubicin & [101] \\
\hline & MG63, SaOS-2 & ULA plates & PLMA, PEGDA, Matrigel® & - & [102] \\
\hline & MG63 (MSCs/osteoblasts) & ULA plates & PLMA & Doxorubicin & [103] \\
\hline \multirow[t]{6}{*}{ Hydrogels } & MG63 & $\begin{array}{l}\text { Cell suspension mixed with } \\
\text { hydrogel solution }\end{array}$ & $\begin{array}{l}\text { Collagen-I, Matrigel }{ }^{\circledR}, \\
\text { agarose, alginate }\end{array}$ & - & [104] \\
\hline & $\mathrm{U} 2 \mathrm{OS}$ & $\begin{array}{l}\text { Cell suspension mixed with } \\
\text { collagen solution }\end{array}$ & Collagen-I & Kinase inhibitor PI103 & [105] \\
\hline & $\begin{array}{l}\text { 143b, MG63, U2OS, } \\
\text { hFOB1.19 }\end{array}$ & $\begin{array}{l}\text { Cell suspension mixed with } \\
3 \% \text { Matrigel }{ }^{\circledR}\end{array}$ & Matrigel® & - & [106] \\
\hline & $\begin{array}{l}\text { MOS, U2OS, 143b, ZK58, } \\
\text { KPD, SaOS-2 }\end{array}$ & $\begin{array}{l}\text { Cell suspension mixed with } \\
\text { hydrogel solution }\end{array}$ & Matrigel $® /$ collagen & Trametinib, TKIs & [107] \\
\hline & MG63 + HUVECs & $\begin{array}{l}\text { Microfluidics-based tech- } \\
\text { nique }\end{array}$ & Alginate, GelMA & - & [108] \\
\hline & Dunn, LM8 & $\begin{array}{l}\text { Cell encapsulation in algi- } \\
\text { nate beads }\end{array}$ & Alginate & NF-kB decoy & [109] \\
\hline \multirow[t]{5}{*}{ Porous scaffolds } & MG63, MNNG & Organic template method & Calcium silicate/chitosan & Doxorubicin & [110] \\
\hline & MG63, SaOS-2 & Direct foaming process & Collagen-I/HA nanocrystals & - & [111] \\
\hline & MG63 & Synthetic porous scaffold & PCL & Dexamethasone & [112] \\
\hline & SaOS-2 & Emulsion casting & Water-in-PDMS & - & [113] \\
\hline & $\begin{array}{l}\text { U2OS, fibroblasts, } \\
\text { HUVECs }\end{array}$ & $\begin{array}{l}\text { Freeze drying to form } \\
\text { porous sponges }\end{array}$ & Silk fibroin & Avastin, MAB208 & [114] \\
\hline
\end{tabular}

GelMA, gelatin methacrylate; HA, hydroxyapatite; HUVECs, human umbilical vein endothelial cells; MAB208, human IL-8/CXCL8 antibody;

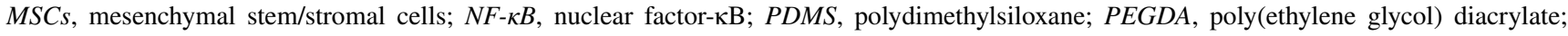
PHEMA, poly(2-hydroxyethyl methacrylate); PLMA, methacryloyl platelet lysate; TKIs, tyrosine kinase inhibitors; ULA, ultra-low attachment 
collagen provides elasticity and flexibility. Moreover, bone continuously undergoes a dynamic resorption and formation cycle; thus, it is under constant stress and mechanical stimuli. Therefore, to mimic the bone environment, an ideal scaffold should not only be biocompatible but should also have an adequate pore size (at least $100 \mu \mathrm{m}$ ) to allow the diffusion of molecules and cells; the mechanical properties should match the ones from bone tissues (Young's modulus of cortical bone varies from 15 to $20 \mathrm{GPa}$ ); and since high levels of extracellular calcium, hypoxia, and low $\mathrm{pH}$ are normal in bone tissues, these properties should also be taken into account when designing biomimetic bone scaffolds [118].

Keeping this in mind, multiple materials have been employed to produce scaffolds to study OS, such as Matrigel ${ }^{\circledR}$, collagen, alginate, chitosan, silk fibroin, agarose, gelatin, bacterial cellulose, and methylcellulose [119, 120]. Matrigel ${ }^{\circledR}$ is one of the most used materials to perform 3D cell culture. For instance, Matrigel ${ }^{\circledR}$ has been used to fabricate a Matrigel®-collagen matrix to evaluate the potential of MEK-ERK mitogen-activated protein kinase inhibitors as novel drugs for OS treatment [107]. Three cell lines were found to be resistant, while other three were sensitive to the inhibitors, with high constitutive ERK activity (signaling pathway related to cancer cell survival). Nevertheless, Matrigel ${ }^{\circledR}$ has disadvantages for the construction of drug screening models; since it is a material of animal origin, some growth factors can affect the tumor's response to specific compounds and there are problems related to batch-tobatch variations, which limits standardization and reproducible results [121].

Another commonly used material is collagen type I. In the bone microenvironment, collagen type I comprises more than $90 \%$ of the organic ECM, playing an important part in OS TME. To recapitulate the stem cell niche of OS, Mg-doped HA and collagen scaffolds were produced by a biomineralization process, allowing the establishment of a proper environment for the maintenance of cancer cell stemness when compared to 2D systems [111]. In a different study, MG63 and 143b cells were embedded in a collagen type I matrix either enriched or not with bone granules [122]. Results demonstrated increased invasion of $143 \mathrm{~b}$ cellular aggregates from the more complex bone-mimicking matrix to an outer collagen, laminin, and fibronectin hydrogel. Differences in ECM composition also influenced OS cell response to doxorubicin treatment. In the more complex ECM, events of resistance to drug-induced death were observed, which emphasizes the importance of the ECM in the tumor's response to chemotherapeutic agents [122].

Finally, alginate-a commonly used polysaccharide in cell and drug encapsulation approaches-has also been applied to produce bone-mimicking scaffolds. Aiming to exploit alginate's bioactive properties, highly porous scaffolds were produced by freeze-drying with a combination of alginate, hydroxyproyltrimethyl ammonium chloride chitosan, and oyster shell powder [123]. The scaffolds were biodegradable and biocompatible when tested with OS cell lines and suitable for cell growth and bone-mimicking applications [123]. In a different approach, a highly metastatic cell line was cultured in alginate beads [109]. The in vitro model was used to perform transfection of the murine LM8 cell line with an NF- $\mathrm{KB}$ oligodeoxynucleotide to suppress the activity of the transcription factor, leading to a marked decrease in pulmonary metastasis in the mice injected with transfected cells [109]. In another study, four different scaffolds (collagen type-I, Matrigel®, alginate, and agarose) were used to culture osteoblasts and OS cells [104]. The proliferation rates of cancer cells were higher in more rigid matrices, and an integrin-mediated focal adhesion pathway was identified as a significant player in the sensitivity of MG63 cells to the ECM, which was not verified in 2D flat surfaces [104]. This elasticity-dependent behavior of OS cells in contrast to the adherent-dependent growth of osteoblasts highlights how the mechanical properties of the ECM can influence cancer cell growth, which is a key aspect to consider when applying novel biomaterials in OS tumor modeling. The use of composite materials or nanoenabled 3D matrices are attractive alternatives in the design of biomaterial-based strategies that enable to fine-tune both the composition and the mechanical properties of 3D scaffolds to better resemble the tissue of interest $[124,125]$.

In this context, given the diverse biophysical environment of the ECM during cancer progression, synthetic biomaterials have been explored to closely tune their features on demand capable of properly mimicking complex dynamic systems. Synthetic biomaterials offer low batch-to-batch variation and the possibility to adjust the properties of the scaffold in a more controllable manner. For instance, the chemical composition, porosity, and stiffness can all be modulated independently to properly mimic the desired environment. Commonly used polymers include synthetic polymers PLA, PEG, polycaprolactone (PCL), and poly(glycolic acid) (PGA) $[119,120]$. These materials have mainly been applied to tissue engineering and drug delivery approaches. For instance, a bone-mimicking scaffold was developed to provide a homing spot for cancer cells [126]. PCL scaffolds coated with calcium phosphate promoted osteogenic differentiation of MSCs and the formation of a specialized bone niche for cancer cell migration [126]. For OS, PEG diacrylate hydrogels have been developed to encapsulate U2OS cells [127]. The optimum matrix stiffness for cancer cell growth was evaluated, showing higher optimum stiffness for OS cells when compared to other cancer cell lines [127]. Moreover, PEG has also been applied in bioengineered scaffolds to study interactions between cancer and bone cells. For instance, 3D printed PEG and HA scaffolds 
were developed to promote the proliferation and interaction of cancer cells with osteoblasts [128].

In addition, more than being used as a 3D tool for cancer modeling, scaffolds have also been studied as biomaterial-based strategies for OS treatment [129]. For instance, thermosensitive poly(lactic-co-glycolic acid) (PLGA)-PEG hydrogels have been applied to localized co-delivery of doxorubicin, cisplatin, and methotrexate [130]. This strategy was then employed in human OS SaOS-2 xenografts in nude mice, which enhanced tumor suppression and increased tumor cell apoptosis. In another study, which aimed to deliver adriamycin-loaded PLGA nanoparticles to bone tumors, nano-HA/collagen scaffolds were used to encapsulate the nanoparticles, resulting in a better release profile and a significant inhibition of cancer cell growth [131].

\section{Multicellular tumor spheroids}

Multicellular tumor spheroids (MCTSs) are one of the most used platforms in cancer research, especially for anti-cancer drug screening. MCTS are able to recapitulate the structure of small solid tumors with cells organized concentrically, mimicking the oxygen, $\mathrm{pH}$, and nutrient gradient observed in tumors [15]. Generally, in the center, there is a lower diffusion of oxygen and nutrients, which leads to a necrotic core formation, whereas more proliferative cells are observed in the outer edges of the spheroids [15, 132]. Multiple techniques can be employed to form MCTS, ranging from the hanging-drop to the liquid-overlay technique based on ultralow attachment (ULA) plates, or other methods based on magnetic levitation, spinner flasks, matrix encapsulation, microfluidics, and 3D bioprinting [115, 133]. Moreover, easy adaptability to high-throughput screening (HTS) makes spheroids an excellent model for drug diffusion studies and to assess the effectiveness of anti-cancer drugs in vitro [133].

In order to evaluate the efficacy of MAP chemotherapy in OS cells, spheroids were formed in non-adherent plates with three different cell lines (143b, MG63, and LM7) [98]. The MG63 and LM7 cell lines exhibited greater resistance to methotrexate when compared to the $143 \mathrm{~b}$ cell line and MG63 monolayers. Similarly, as a way to test the effect of doxorubicin on the viability of cancer spheroids in real time, U2OS spheroids were established in ULA plates [134]. Results showed higher resistance of OS spheroids when compared to $2 \mathrm{D}$ cultures. In addition, since the spheroids were still viable after one day of treatment, cytotoxicity of doxorubicin seemed to happen after endocytosis [134]. OS spheroids have also been used to analyze the role of cancer stem cells in anti-cancer drug resistance. Cancer stem cells were isolated from the MNNG/HOS cell line by culturing OS cells in ULA plates [135]. The tumor cells formed spheroids and after passaging the cells, third-generation spheroids were reintroduced into adherent conditions and allowed to grow in monolayer. The cancer stem cells demonstrated MSC markers (CD73, CD90, CD13, CD105), self-renewal, and expression of pluripotency properties (differentiation into osteogenic, chondrogenic, and adipogenic lineages). Besides, they were more resistant to chemo and radiotherapy when compared to the parental cell line. In a different study, a double culture spheroid model was developed to study the differences between bone regeneration and chemotherapy in early- and late-stage OS [101]. SaOS-2 cells and MSCs were seeded on non-adherent micromolds to form spheroids with different ratios (MSCs:SaOS-2 3:1, early, and 1:3, late). Early-stage spheroids were generally smaller, produced more ECM, and presented a lower expression of $\beta$-catenin, RUNX2, and alkaline phosphatase (ALP), known OS prognostic markers. The addition of PDGF and BMP-2 predominantly affected the early-stage model by inducing a marked increase in size and ECM production, demonstrating that cancer cells were less sensitive to these osteogenic growth factors. Moreover, the combination of growth factors and doxorubicin led to inhibition of the stimulatory effects previously detected, highlighting a limited regeneration capability when chemotherapeutic agents are employed [101].

Furthermore, spheroid-based models have been utilized in combination with hydrogels to perform invasion studies and to better mimic the 3D TME, including the ECM as an essential factor in cancer cell proliferation and anticancer drug response. To investigate the influence of cell arrangement in drug screening, a hydrogel model was used to encapsulate OS cells [132]. MG63 spheroids were formed by the liquid overlay technique in ULA plates and encapsulated in either gelatin methacrylate (GelMA) or Matrigel ${ }^{\circledR}$. The same was performed with randomly dispersed OS cells within the hydrogels. Results showed higher invasion potential and drug resistance in the encapsulated OS spheroids when compared to the cell-laden hydrogels [132]. In a different approach, a human methacryloyl platelet lysate (PLMA) hydrogel was fabricated to study the invasion potential of OS spheroids [103]. This biomimetic material of human origin potentiated the proliferation and invasion of MG63 spheroids that were embedded in PLMA hydrogels and cocultured with human osteoblasts and bone marrow-derived MSCs. The invasion kinetics could be controlled by variations in the hydrogel stiffness and was higher in the coculture conditions. Moreover, MSCs migrated toward the OS spheroids and improved tumor cell resistance to doxorubicin treatment, thus showing to accurately recapitulate OS events using an in vitro platform suitable for drug screening studies [103]. In another study, MG63 spheroids were cultured over a monolayer of endothelial cells [136]. Rapid tumor cell invasion of the endothelial surface was detected as well as the formation of endothelial cell tubule-like structures that reached the tumor spheroids. Higher expression of angiogenic factors (VEGF, CXCR4, intracellular adhesion 
molecule 1 (ICAM1)) was detected, thus confirming the angiogenic potential of cancer cells cultured in contact with endothelial cells [136].

Overall, these studies clearly demonstrate the need for novel spheroid-based OS models. Although some experiments have been done by culturing tumor cells with osteoblasts and MSCs [103] or endothelial cells [136], only one study has reported the establishment of heterotypic MCTS (with cancer cells and MSCs) to model OS in vitro [101]. Thus, the inclusion of stromal cells, such as MSCs, fibroblasts, macrophages, $\mathrm{T}$ cells, or bone cells, could be an alternative to develop 3D models that more accurately resemble the OS TME. For other cancer types, multiple studies have reported a successful double culture of spheroids with fibroblasts, MSCs, immune cells, endothelial cells, and other non-malignant cells of the TME [137]. A few experiments have also been performed with triple culture spheroids with tumor cells, fibroblasts, and immune cells (monocytes/macrophages) [138-140]. These studies have shown the potential of exploring more complex MCTS to mimic the TME and that are suitable for drug screening studies in vitro. However, despite their simplicity and HTS capability, similarly to scaffold-based assays, limitations involve the lack of controllability in terms of cell arrangement within the spheroids, which is mostly based on self-aggregation, and thus does not mimic the physiological conditions in some cases. For instance, CAFs usually surround the tumor core and do not penetrate into the spheroid's center, as it has been reported by different studies [138, 141]. Other difficulties arise from the challenge in controlling the number of immune cells or slower proliferating cells within the spheroids' structure, which limits reproducibility and may compromise the ability to test immunotherapies [138].

\section{Tumor organoids}

Tumor organoids represent another relevant cancer modeling tool, bringing the advantage of preserving patient-specific tissue characteristics and heterogeneity over multiple passages and recapitulating the native tumor formation in vitro [16]. Tumor organoids are originated from patient/mousederived tumor cells or by genetic editing of induced pluripotent stem cells that are cultured on a matrix, normally Matrigel ${ }^{\circledR}$ or collagen [16, 142]. Limitations of this model include difficulty in reaching in vivo-like maturity, timeconsuming protocols, and lack of stromal cells and vasculature [143]. Most of the tumor organoid models have been described for epithelial-derived cancers [16]. Nevertheless, a recent study reported the establishment of an organoid culture system of lung metastatic OS tissue [144]. Patientderived tumor tissues from OS bone or lung metastatic lesions were cultured en bloc in collagen type I hydrogels or as single cells embedded in Matrigel ${ }^{\circledR}$. The organoids formed after 7 days and could be propagated for at least 6 months. The OS organoids preserved the morphology of typical human OS tumors and expression of vimentin and transcription factor Sox9. Interestingly, the OS lung organoids retained a similar $\mathrm{T}$ cell distribution at earlier passages, which could potentiate their use as an immunotherapy screening platform. Effectively treating organoids with antiPD-1 monoclonal antibodies led to higher numbers of $\mathrm{CD}^{+}$ $\mathrm{T}$ cells, thus attesting $\mathrm{T}$ cell activation and faithful recapitulation of the immune TME in vitro. The OS organoids were also cryopreserved, showing no differences in viability, thus suggesting the possibility of creating an OS organoid biobank [144].

\section{Microfluidic platforms}

Microfluidic-based 3D models involve microchips with specific designs that gather the advantages of culturing cells within biomimetic transparent microchannels using smaller volumes. This renders microfluidic-based models less expensive than other approaches, and also allows facile imaging analysis as well as HTS adaptability for drug screening studies $[18,115]$. Some drawbacks include specialized skills to produce the chips; some technical impairments due to shear stress in the channels, which affect cell proliferation by hindering laminar flow, and few alternative materials to produce the chips as polydimethylsiloxane (PDMS), the most commonly used material, might absorb small molecules $[18,145]$. In the case of OS, only a few studies have reported their utilization. These studies mostly focused on the influence of molecular gradients in cell morphology, or the adhesive properties of OS cells under shear flow or at various temperatures/pHs. In one study, the secretion of VEGF type A from MG63 cells was investigated [100]. OS cells were cultured either in a monolayer or in a spheroid model fabricated in microfluidic chips. The results demonstrated lower cell viability under higher stress levels (due to inhibition of HIF and decreased nutrient supply) in both cell culture models. However, in monoculture, the secretion of VEGF decreased in stressful conditions, which does not correspond to the in vivo situation [100]. In another study, a microfluidic platform was developed to test the efficacy of methotrexate and methotrexate-loaded nanoparticles [146]. U2OS cells were seeded inside the microfluidic chips and cytotoxic analysis was performed after $72 \mathrm{~h}$ of treatment recirculation. The loaded nanoparticles greatly reduced the cell population to less than $20 \%$ for lecithin-polyvinyl alcohol (LEC-PVA) nanoparticles and to $2.3 \%$ for LEC-Tween nanoparticles, which was significantly more efficient than the free drug [146].

Furthermore, since microfluidic chips can be adapted for culture under dynamic conditions, they are useful tools to mimic the vasculature in vitro [147] and to study the 
metastatic cascade and the migration of tumor cells from the primary tumor $[18,148]$. However, no experiments have been conducted to develop an accurate microfluidic platform to unveil the metastatic process of OS cells to the lung. Nonetheless, the lung microenvironment has been extensively studied in organ-on-a-chip platforms [18], which could be explored to analyze the interactions between OS cells and the lung environment. The lung-on-a-chip was one of the first systems developed to include endothelial cells and lung epithelial cells as well as to allow the simulation of breathing motions in vitro [149]. Later, the same platform was adapted for cancer experiments by culturing non-small-lung cancer cells in the device [150]. It was revealed that breathing motions suppressed tumor cell proliferation and invasion, and promoted resistance to tyrosine kinase inhibitor therapy, which appeared to be related to signaling changes of epidermal growth factor receptor (EGFR) and MET protein kinase.

Given that the bone is a common organ for metastasis formation, mainly in patients with metastatic breast and prostate cancer [151], multiple models have been developed to emulate the bone microenvironment in vitro [152]. In one study, fibroblasts, endothelial cells, and tumor cells were co-cultured in a composite gel of HA and fibrin inside a microfluidic chip [153]. Higher concentrations of HA reduced the pore size of the scaffolds, altered their mechanical properties, and reduced cell migration and angiogenic sprout formation. Regarding the extravasation of breast cancer cells into a bone-mimicking environment, another microfluidic platform was utilized to co-culture tumor cells, endothelial cells, human bone marrow-derived MSCs, and osteoblast-differentiated cells embedded in a fibrin gel to recapitulate the bone matrix [154]. The extravasation rates were substantially higher in the bone-mimicking microenvironment, whereas microvasculature permeabilities were higher in myoblast-containing matrices. This demonstrates how distinct microenvironments can influence cancer progression and how this is an important factor to keep in mind when developing cell culture models for drug screening. In another study, a 3D vascularized bone model was established by culturing endothelial cells, bone marrow-derived MSCs, osteoblasts, and osteoclast precursors in a collagen/fibrin hydrogel enriched with calcium phosphate $(\mathrm{CaP})$ nanoparticles [155]. The combination of all these cells and the presence of $\mathrm{CaP}$ nanoparticles promoted the differentiation of osteoblasts and osteoclasts compared to monocultures, highlighting the importance of 3D microenvironment composition to accurately recapitulate biological responses in vitro. In summary, the potential of microfluidic-based models to study OS remains an unbeaten path, with full freedom to explore the capabilities of these platforms as powerful drug screening tools and in unveiling unknown processes in OS progression and metastasis, as it has been investigated for other cancer types.

\section{Modeling metastasis: are 3D in vitro models enough?}

Around $90 \%$ of cancer deaths are related to metastasis formation even though only around $0.01 \%$ of cancer cells can effectively form secondary tumors, which poses the question: how such an inefficient process can be fatal for so many patients? The metastatic cascade involves complex $3 \mathrm{D}$ interactions between cancer cells, the secondary organ, and the ECM. Hence, models that can better resemble key aspects of the metastatic cascade are essential for a better understanding of the proliferation of secondary tumors in distant organs. Given the complex metastatic cascade that generates a successful seeding of malignant cancer cells in a distant metastatic niche, it is difficult to study cancer cell dissemination outside of the whole organism. Therefore, animal models are essential for these studies as well as to evaluate the efficacy, safety, and biodistribution of novel therapeutics [156]. An ideal model of OS should allow the spontaneous formation of the primary OS tumor in the bone and the development of lung metastases within an immunocompetent host. Conventional models for studying novel therapies and metastasis most frequently involve xenogeneic and syngeneic mouse models [157]. Currently, there is no robust OS animal model that can completely recapitulate the formation of bone tumors in the same anatomical locations as in humans and with spontaneous development of lung metastases. Xenogeneic models involve the utilization of immunodeficient animals injected with human tumor cell lines, whereas syngeneic models are immunocompetent but involve the utilization of mouse tumor cells and the tumor formation is not spontaneous [157]. Another relevant strategy has been to study the spontaneous formation of OS in dogs, which represent a large population of animals affected by the disease with similar biological behavior, genetic instability, and clinical progression patterns as in humans [158].

The inclusion of complementary systems, such as animal model-related technology, ex vivo tissue approaches, or bioengineered 3D culture models, has recently gained wider appeal. Intravital video microscopy or window for high-resolution imaging in the lung encompasses a small circular window that is implanted in the chest cavity of a live mouse [159]. This assay permits serial imaging of the same area of the lung for up to 2 weeks, which enables to study the establishment of micrometastases. One key disadvantage of this technique is the depth of imaging, which is limited to between 200 and $700 \mu \mathrm{m}$ depending on the type of microscope used [159]. The pulmonary metastasis assay (PuMA) is an ex vivo model in which lung explants are co-cultured 
with fluorescently labeled tumor cells and maintained in in vitro culture for up to 21 days. OS cells cultured on this model have been shown to retain the phenotypic features of cancer cells [160]. Indeed, multiple studies have investigated the proliferation of OS cells in ex vivo lung tissues and how gene manipulation or drug treatments affect lung metastases $[90,160,161]$. The advantages of this assay encompass the inclusion of a relevant 3D microenvironment to study OS metastasis to the lung and easy cell imaging compatibility by fluorescence microscopy. The major limitation is that some cell lines are not compatible with this model and some observations are only possible for 21 days due to the destruction of lung parenchymal cells over time [36].

Furthermore, novel bioengineered cancer models (spheroids, organoids, tumor-on-a-chip platforms) are crucial breakthroughs in the field of cancer research, allowing for a better recapitulation of tumor-specific events in vitro while enabling a relatively simple recreation of the TME and the metastatic process [148, 162, 163]. For instance, in an attempt to merge the benefits of microfluidics and spheroidbased assays, a 3D culture platform has been developed for scale-up production of spheroids in an injection-molded plastic array device [164]. This platform was then used to study tumor angiogenesis by culturing endothelial cells that organized in perfusable blood vessel networks and migrated toward the center of MCTS with fibroblasts and cancer cells. Furthermore, multi-organ-on-a-chip devices have also been explored in the context of metastasis [165]. In one study, a metastasis-on-a-chip model was engineered to assess the preference of cancer cells in terms of metastatic sites [166]. Cancer spheroids were embedded in a synthetic ECM hydrogel and seeded in a compartment of the device. The migration patterns of the circulating cancer cells were evaluated under recirculating fluid flow to either an endothelium, lung, or liver compartment. Cancer cells preferentially migrated to the lung and liver constructs, thus replicating the situation in vivo [166]. This rather simple approach highlights the potential of these platforms that have also been thoroughly explored to culture multi organ-like constructs in combination to assess biological responses to drug administration [167].

In terms of metastasis modeling, tumor-on-a-chip approaches present numerous advantages, allowing (i) compartmentalization of cells, thus being possible to introduce multiple cell types in co-culture; (ii) flow and gradient control that allows, for example, the maintenance of endothelial cells in a dynamic culture and the perfusion of particles and immune cells to target cancer metastases; (iii) real-time analysis of cell migration to study cancer cell invasion, extravasation, or intravasation; (iv) control of mechanical forces such as breathing motions or ECM stiffness that may influence cancer cell responses; (v) facile data analysis and imaging through fluorescence confocal imaging [148].
Nonetheless, a complete recapitulation of the complex metastatic process in vitro is not yet possible. Reducing production costs as well as specialized and complex equipment (pumps, tubing, etc.) involved the platforms' production, and preserving patient-specific tumor heterogeneity, the TME immune landscape, and the tumor's vasculature is a significant hurdle to overcome to accurately recapitulate the metastatic cascade in vitro. Moreover, some chip designs may hinder cell retrieval and the small size of some platforms might impair downstream analysis (e.g., flow cytometry analysis and gene expression studies) since the number of cells may not be sufficient to reach the equipment's sensibility. Recently, 3D bioprinting has greatly contributed to an easy microfluidic chip fabrication process with lower costs, and some pump-free alternatives have also been developed and commercialized, thus highlighting the potential of these emerging technologies to properly culture cells in vitro [168-170]. Despite these problems that still need to be tackled, 3D metastasis models have proven to be physiologically relevant and an important tool in the advent of personalized medicine, drug screening, and metastasis studies in vitro. In the specific case of OS, none of these models have been explored, which leaves multiple possibilities to investigate their potential for OS in vitro modeling and drug screening studies (Fig. 4). Therefore, considering these models in the preclinical pipeline will certainly not only help to reduce the number of animals in cancer research but also expedite the drug development pathway toward a more efficient process with fewer unexpected failures in clinical trials.

\section{Remaining concerns and future perspectives}

Over the past decade, 3D culture models have become increasingly available, with multiple companies producing novel and standardized platforms for 3D cell culture and even high-throughput drug screening. However, in the pharmaceutical industry, preclinical research is still primarily based on 2D assays and animal models. To bring 3D models into this setting, these novel platforms need to prove that they are reliable and reproducible systems. Moreover, they must have the capability to be scaled up to an industrial setting to test thousands of compounds in a short time frame. Nevertheless, some challenges still need to be addressed for this to be a reality. For instance, issues related to medium composition, cell sources, and variability/reproducibility still need to be tackled, as different cell types have specific nutrient requirements, implying that the choice of the correct culture medium for the co-culture of multiple cell types may be an additional challenge [171]. Possible solutions include mixed medium, supplemented medium, and partitioned culture conditions [171]. Microfluidic platforms have also shown great potential for culture medium optimization. In 


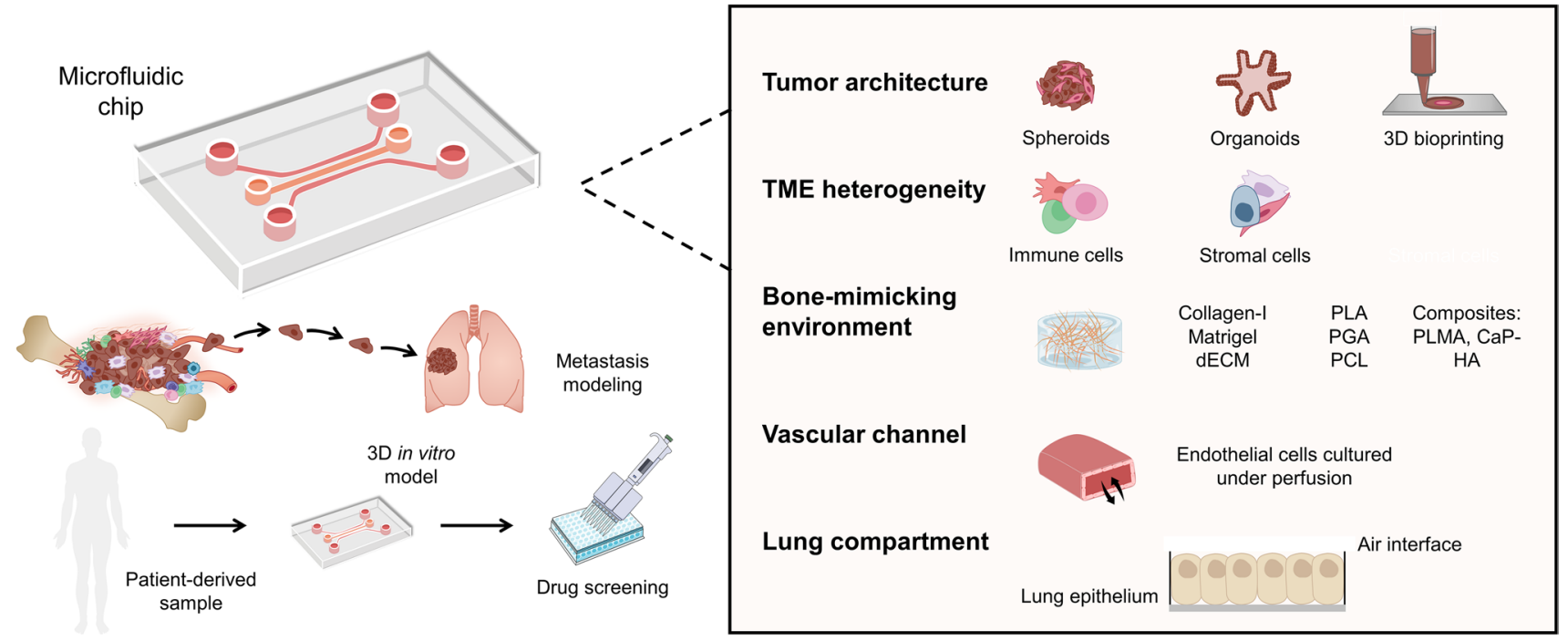

Fig. 4 Framework for the development of novel osteosarcoma bioengineered models. Schematic representation of how innovative 3D models can be employed to study the metastatic spread of OS cells to the lung on a microfluidic chip adaptable for culture under dynamic conditions. OS cells might be cultured on a separate compartment as spheroids or organoids that can be assembled with other cell types to resemble the TME, namely immune cells (macrophages, lymphocytes) and stromal cells (MSCs, fibroblasts, osteoblasts, osteoclasts), on a bone-mimicking environment composed by natural hydrogels (collagen type I, Matrigel ${ }^{\circledR}$, decellularized matrices (dECM)),

a recent study, a microdevice was developed to analyze the effects of culture medium composition in cell morphology and proliferation through imaging techniques [172]. Additionally, the utilization of patient-derived cells versus cell lines still needs to be further explored [173]. In the case of OS, since there is a high heterogeneity between patients, the cell source is an important aspect to consider. Cancer cell lines are a staple in cancer research, representing an almost unlimited source in comparison to the limited availability of patient-derived material. However, since multiple cell line-dependent results have been reported, selecting a proper cell line should be carefully analyzed for each study [174]. In contrast, patient-derived cells represent patientspecific features and have been extensively explored in the field of personalized medicine. Drawbacks related to their use include difficult culture conditions, short-term expansion, rapid loss of specific phenotypes in vitro, and high variability between donors [175]. Moreover, patient-derived cells are also relevant to introduce crucial TME components in novel 3D in vitro models. Tumor organoid protocols have greatly evolved to tackle some of these problems, and some studies, including for OS, have reported the inclusion of immune cells, allowing immunotherapy testing [144, 176]. Finally, improving these technologies' reproducibility and high-throughput capability is another obstacle to overcome, which includes avoiding batch-to-batch variations of synthetic polymers (PGA, PLA), or composite materials (PLMA, CaP-HA). OS cells growing on this compartment should be able to migrate into the vascular channel with endothelial cells and reach the lung compartment. Importantly, the platform should be adaptable for drug screening studies and to evaluate potential pharmacological targets to inhibit the metastatic spread of OS cells. To further enhance the predictable value, patient-derived tissues could be used, thus harnessing the advantages of personalized medicine and improving the preclinical pipeline before performing animal studies

animal-sourced components, such as fetal bovine serum or Matrigel ${ }^{\circledR}[177,178]$. Human derivatives are already being explored, including the utilization of xeno-free alternatives for cell culture from human origin [177], synthetic biomaterials, or human-derived composite materials, such as PLMA hydrogels, which have proven successful for OS drug screening $[102,103]$. In addition, the emerging applicability of 3D bioprinting in the design of complex and reproducible 3D constructs has been a crucial breakthrough in tissue engineering and cancer research. For OS, this technology has not yet been employed; nonetheless, its advantages, including the precise spatiotemporal deposition of cells and biomaterials under a well-defined architecture, its microscale resolution, and commercial availability, make it a promising technology to be explored [179-181]. Moreover, 3D bioprinting has been used to aid the fabrication of MCTS in a high-throughput fashion, which also highlights the ability to culture multiple cell types (such as fibroblasts, cancer, and endothelial cells) within specific niches [182]. For bonerelated studies, experiments performed with OS cell lines have shown the possibility to incorporate OS cells into printable bioinks composed of alginate, gelatin, polyphosphate, and agarose or biosilica [183, 184]. For metastasis modeling, stereolithography-based 3D printing has been applied to create a breast cancer model consisting of an osteoblastladen nanostructured bone matrix, a vascular channel, and 
a tumor region [185]. The bioinks used (GelMA, PEGDA, HA nanocrystals) were optimized for cell survival and the cancer cells were able to migrate through the endothelial channel into the bone matrix.

Despite the benefits of 3D-based assays, the transition from 2D cultures to novel culture systems has been rather slow. Some reasons that can justify this slow transition include the higher cost of these technologies, the difficulty to adapt to HTS, complex optimization steps associated with low reproducibility, the powerful imaging technology necessary, and limited accessibility in some research laboratories. In addition, given the wide range of available culture platforms, it is challenging to compare results between different 3D and 2D cultures, and there is a clear lack of comparison with patient responses, which is essential for translating and validating these novel models. Besides, the complexity of these models will definitely grow with the addition of multiple cell types, ECM components, and biomaterials, which will further hinder downstream analysis since, for instance, some cells do not express specific markers. Therefore, it is necessary to find a balance between complexity and readability to develop physiologically relevant models that can be easily analyzable. Fortunately, some of these hurdles are already being undertaken and there are now a growing number of commercial products related to 3D cell culture and even metastasis modeling in vitro, such as ECM-mimicking hydrogels, spheroid-related products, and microfluidic platforms [186, 187], which may contribute to a wider acceptance and exploration of these platforms' potential in more research laboratories.

Overall, preclinical research still relies mostly on 2D and animal models, especially for anti-cancer drug screening. The complexity and physiological relevance of animal models are still unmatched in vitro. Therefore, reliable animal models are still needed to evaluate the metabolism and efficacy of novel drugs, to study the metastatic cascade of cancer as well as to validate novel 3D in vitro platforms. Besides, in vivo studies coupled with novel technologies such as intravital video microscopy and ex vivo approaches (tumor organoids, PuMA assay) can enhance the refinement of animal experiments related to cancer metastasis. In addition, bioengineered 3D models are also appropriate assays to reduce unnecessary in vivo studies. By allowing a better representation of the tumor's pathophysiology in vitro, these novel 3D models can be used at an early preclinical stage to eliminate possible drug candidates and to further improve our knowledge of cancer-related events, including the metastatic spread of tumor cells or the resistance to therapeutics. In the specific case of OS, most of the presented technologies remain unexplored. As most of the OS deaths are related to pulmonary metastases and given the relevant role of TME in metastasis formation, many of these platforms can be adapted to properly model the OS TME in vitro and better understand the events of OS origin, progression, and metastasis as well as to find novel targets to develop more effective treatments in the future.

Acknowledgements This paper was financed by Portuguese funds through FCT-Fundação para a Ciência e a Tecnologia.

\section{Declarations}

Competing interests The authors declare no competing interests.

\section{References}

1. Durfee RA, Mohammed M, Luu HH. Review of osteosarcoma and current management. Rheumatol Ther. 2016;3:221-43. https://doi.org/10.1007/s40744-016-0046-y.

2. Valery PC, Laversanne M, Bray F. Bone cancer incidence by morphological subtype: a global assessment. Cancer Causes Control. 2015;26:1127-39. https://doi.org/10.1007/s10552-015-0607-3.

3. Kansara M, Teng MW, Smyth MJ, Thomas DM. Translational biology of osteosarcoma. Nat Rev Cancer. 2014;14:722-35. https://doi.org/10.1038/nrc3838.

4. Casali PG, Bielack S, Abecassis N, Aro HT, Bauer S, Biagini $\mathrm{R}$, et al. Bone sarcomas: ESMO-PaedCan-EURACAN clinical practice guidelines for diagnosis, treatment and follow-up. Ann Oncol. 2018;29:iv79-95. https://doi.org/10.1093/annonc/ $\operatorname{mdy} 310$.

5. Friebele JC, Peck J, Pan X, Abdel-Rasoul M, Mayerson JL. Osteosarcoma: a meta-analysis and review of the literature. Am J Orthop (Belle Mead NJ). 2015;44:547-53.

6. Corre I, Verrecchia F, Crenn V, Redini F, Trichet V. The osteosarcoma microenvironment: a complex but targetable ecosystem. Cells. 2020;9:976. https://doi.org/10.3390/cells9040976.

7. Gill J, Gorlick R. Advancing therapy for osteosarcoma. Nat Rev Clin Oncol. 2021;18:609-24. https://doi.org/10.1038/ s41571-021-00519-8.

8. Duval K, Grover H, Han LH, Mou Y, Pegoraro AF, Fredberg J, et al. Modeling physiological events in $2 \mathrm{D}$ vs. $3 \mathrm{D}$ cell culture. Physiology. 2017;32:266-77. https://doi.org/10.1152/physiol. 00036.2016.

9. Emon B, Bauer J, Jain Y, Jung B, Saif T. Biophysics of tumor microenvironment and cancer metastasis - a mini review. Comput Struct Biotechnol J. 2018;16:279-87. https://doi.org/10.1016/j. csbj.2018.07.003.

10. Jensen $C$, Teng $Y$. Is it time to start transitioning from $2 D$ to $3 D$ cell culture? Front Mol Biosci. 2020;7:1-15. https://doi.org/10. 3389/fmolb.2020.00033.

11. Hussey GS, Dziki JL, Badylak SF. Extracellular matrix-based materials for regenerative medicine. Nat Rev Mater. 2018;3:15973. https://doi.org/10.1038/s41578-018-0023-x.

12. Liu Z, Vunjak-Novakovic G. Modeling tumor microenvironments using custom-designed biomaterial scaffolds. Curr Opin Chem Eng. 2016;11:94-105. https://doi.org/10.1016/j.coche.2016.01. 012.

13. Rijal G, Li W. 3D scaffolds in breast cancer research. Biomaterials. 2016;81:135-56. https://doi.org/10.1016/j.biomaterials.2015. 12.016 .

14. Ferreira LP, Gaspar VM, Mano JF. Decellularized extracellular matrix for bioengineering physiomimetic $3 \mathrm{D}$ in vitro tumor models. Trends Biotechnol. 2020; 1-18. https://doi.org/10.1016/j. tibtech.2020.04.006 
15. Nunes AS, Barros AS, Costa EC, Moreira AF, Correia IJ. 3D tumor spheroids as in vitro models to mimic in vivo human solid tumors resistance to therapeutic drugs. Biotechnol Bioeng. 2019;116:206-26. https://doi.org/10.1002/bit.26845.

16. Drost J, Clevers H. Organoids in cancer research. Nat Rev Cancer. 2018;18:407-18. https://doi.org/10.1038/s41568-018-0007-6.

17. Heinrich MA, Liu W, Jimenez A, Yang J, Akpek A, Liu X, et al. 3D Bioprinting: from benches to translational applications. Small. 2019;15:1-47. https://doi.org/10.1002/smll.201805510.

18. Sontheimer-Phelps A, Hassell BA, Ingber DE. Modelling cancer in microfluidic human organs-on-chips. Nat Rev Cancer. 2019;19:65-81. https://doi.org/10.1038/s41568-018-0104-6.

19. Seeley RRTDS\& PT, VanPutte C, Regan J, Seeley RRTDS\& PT, Stephens T, Tate P. Seeley's anatomy \& physiology. 11th Editi. New York, NY: McGraw-Hill; 2017.

20. Martin TJ, Sims NA. RANKL/OPG; Critical role in bone physiology. Rev Endocr Metab Disord. 2015;16:131-9. https://doi.org/ 10.1007/s11154-014-9308-6.

21. Florencio-Silva R, Sasso GRDS, Sasso-Cerri E, Simões MJ, Cerri PS. Biology of bone tissue: structure, function, and factors that influence bone cells. Biomed Res Int. 2015;2015:1-17. https://doi.org/10.1155/2015/421746.

22. Ikebuchi Y, Aoki S, Honma M, Hayashi M, Sugamori Y, Khan $\mathrm{M}$, et al. Coupling of bone resorption and formation by RANKL reverse signalling. Nature. 2018;561:195-200. https://doi.org/10. 1038/s41586-018-0482-7.

23. Mutsaers AJ, Walkley CR. Cells of origin in osteosarcoma: mesenchymal stem cells or osteoblast committed cells? Bone. 2014;62:56-63. https://doi.org/10.1016/j.bone.2014.02.003.

24. Lin Y-H, Jewell BE, Gingold J, Lu L, Zhao R, Wang LL, et al. Osteosarcoma: molecular pathogenesis and iPSC modeling. Trends Mol Med. 2017;23:737-55. https://doi.org/10.1016/j. molmed.2017.06.004.

25. Håkelien A-M, Bryne JC, Harstad KG, Lorenz S, Paulsen J, Sun $\mathrm{J}$, et al. The regulatory landscape of osteogenic differentiation. Stem Cells. 2014;32:2780-93. https://doi.org/10.1002/stem. 1759.

26. Endo-Munoz L, Evdokiou A, Saunders NA. The role of osteoclasts and tumour-associated macrophages in osteosarcoma metastasis. Biochim Biophys Acta - Rev Cancer. 2012;1826:43442. https://doi.org/10.1016/j.bbcan.2012.07.003.

27. Abarrategi A, Tornin J, Lucia MC, Hamilton A, Enrique MC, Rodrigo JP, et al. Osteosarcoma: cells-of-origin, cancer stem cells, and targeted therapies. Stem Cells Int. 2016;2016. https:// doi.org/10.1155/2016/3631764

28. Hattinger CM, Patrizio MP, Fantoni L, Casotti C, Riganti C, Serra M. Drug resistance in osteosarcoma: emerging biomarkers, therapeutic targets and treatment strategies. Cancers (Basel). 2021;13:2878. https://doi.org/10.3390/cancers13122878.

29. Martins-Neves SR, Paiva-Oliveira DI, Wijers-Koster PM, Abrunhosa AJ, Fontes-Ribeiro C, Bovée JVMG, et al. Chemotherapy induces stemness in osteosarcoma cells through activation of Wnt/ק-catenin signaling. Cancer Lett. 2016;370:286-95. https:// doi.org/10.1016/j.canlet.2015.11.013.

30. Yao Z, Han L, Chen Y, He F, Sun B, Kamar S, et al. Hedgehog signalling in the tumourigenesis and metastasis of osteosarcoma, and its potential value in the clinical therapy of osteosarcoma. Cell Death Dis. 2018;9:701. https://doi.org/10.1038/ s41419-018-0647-1.

31. Danieau G, Morice S, Rédini F, Verrecchia F, Le RBB. New insights about the $\mathrm{Wnt} / \beta$-catenin signaling pathway in primary bone tumors and their microenvironment: a promising target to develop therapeutic strategies? Int J Mol Sci. 2019;20:1-22. https://doi.org/10.3390/ijms20153751.

32. Goldstein SD, Trucco M, Guzman WB, Hayashi M, Loeb DM. A monoclonal antibody against the Wnt signaling inhibitor dickkopf-1 inhibits osteosarcoma metastasis in a preclinical model. Oncotarget. 2016;7:21114-23. https://doi.org/10.18632/ oncotarget.8522.

33. Saraf AJ, Fenger JM, Roberts RD. Osteosarcoma: accelerating progress makes for a hopeful future. Front Oncol. 2018;8:1-7. https://doi.org/10.3389/fonc.2018.00004.

34. Grignani G, Palmerini E, Ferraresi V, D’Ambrosio L, Bertulli $\mathrm{R}$, Asaftei SD, et al. Sorafenib and everolimus for patients with unresectable high-grade osteosarcoma progressing after standard treatment: a non-randomised phase 2 clinical trial. Lancet Oncol. 2015;16:98-107. https://doi.org/10.1016/S1470-2045(14) 71136-2.

35. Fares J, Fares MY, Khachfe HH, Salhab HA, Fares Y. Molecular principles of metastasis: a hallmark of cancer revisited. Signal Transduct Target Ther. 2020;5:28. https://doi.org/10.1038/ s41392-020-0134-x.

36. Fan TM, Roberts RD, Lizardo MM. Understanding and modeling metastasis biology to improve therapeutic strategies for combating osteosarcoma progression. Front Oncol. 2020;10:1-27. https://doi.org/10.3389/fonc.2020.00013.

37. Baglio SR, Lagerweij T, Pérez-Lanzón M, Ho XD, Léveillé N, Melo SA, et al. Blocking tumor-educated MSC paracrine activity halts osteosarcoma progression. Clin Cancer Res. 2017;23:372133. https://doi.org/10.1158/1078-0432.CCR-16-2726.

38. Mazumdar A, Urdinez J, Boro A, Migliavacca J, Arlt MJE, Muff $\mathrm{R}$, et al. Osteosarcoma-derived extracellular vesicles induce lung fibroblast reprogramming. Int J Mol Sci. 2020;21:5451. https:// doi.org/10.3390/ijms21155451.

39. Li S. The basic characteristics of extracellular vesicles and their potential application in bone sarcomas. J Nanobiotechnology. 2021;19:277. https://doi.org/10.1186/s12951-021-01028-7.

40. Alfranca A, Martinez-Cruzado L, Tornin J, Abarrategi A, Amaral $\mathrm{T}$, de Alava E, et al. Bone microenvironment signals in osteosarcoma development. Cell Mol Life Sci. 2015;72:3097-113. https://doi.org/10.1007/s00018-015-1918-y.

41. Navet B, Ando K, Vargas-Franco J, Brion R, Amiaud J, Mori K, et al. The intrinsic and extrinsic implications of RANKL/RANK signaling in osteosarcoma: from tumor initiation to lung metastases. Cancers (Basel). 2018;10:398. https://doi.org/10.3390/cance rs10110398.

42. Verrecchia F, Rédini F. Transforming growth factor- $\beta$ signaling plays a pivotal role in the interplay between osteosarcoma cells and their microenvironment. Front Oncol. 2018;8:1-11. https:// doi.org/10.3389/fonc. 2018.00133 .

43. Garimella R, Washington L, Isaacson J, Vallejo J, Spence M, Tawfik O, et al. Extracellular Membrane vesicles derived from 143B osteosarcoma cells contain pro-osteoclastogenic cargo: a novel communication mechanism in osteosarcoma bone microenvironment. Transl Oncol. 2014;7:331-40. https://doi.org/10. 1016/j.tranon.2014.04.011.

44. Shi Y, Du L, Lin L, Wang Y. Tumour-associated mesenchymal stem/stromal cells: emerging therapeutic targets. Nat Rev Drug Discov. 2016;16:35-52. https://doi.org/10.1038/nrd.2016.193.

45. Pietrovito L, Leo A, Gori V, Lulli M, Parri M, Becherucci V, et al. Bone marrow-derived mesenchymal stem cells promote invasiveness and transendothelial migration of osteosarcoma cells via a mesenchymal to amoeboid transition. Molecular Oncology. 2018 659-676. https://doi.org/10.1002/1878-0261. 12189

46. Zheng Y, Wang G, Chen R, Hua Y, Cai Z. Mesenchymal stem cells in the osteosarcoma microenvironment: their biological properties, influence on tumor growth, and therapeutic implications. Stem Cell Res Ther. 2018;9:1-9. https://doi.org/10.1186/ s13287-018-0780-x.

47. Quante M, Tu SP, Tomita H, Gonda T, Wang SSW, Takashi $\mathrm{S}$, et al. Bone marrow-derived myofibroblasts contribute to 
the mesenchymal stem cell niche and promote tumor growth. Cancer Cell. 2011;19:257-72. https://doi.org/10.1016/j.ccr. 2011.01.020.

48. Vallabhaneni KC, Hassler MY, Abraham A, Whitt J, Mo YY, Atfi A, et al. Mesenchymal stem/stromal cells under stress increase osteosarcoma migration and apoptosis resistance via extracellular vesicle mediated communication. PLoS One. 2016;11:1-14. https://doi.org/10.1371/journal.pone.0166027.

49. Tu B, Peng Z-X, Fan Q-M, Du L, Yan W, Tang T-T. Osteosarcoma cells promote the production of pro-tumor cytokines in mesenchymal stem cells by inhibiting their osteogenic differentiation through the TGF- $\beta / \mathrm{Smad} 2 / 3$ pathway. Exp Cell Res. 2014;320:164-73. https://doi.org/10.1016/j.yexcr.2013.10.013.

50. Cortini M, Massa A, Avnet S, Bonuccelli G, Baldini N. Tumoractivated mesenchymal stromal cells promote osteosarcoma stemness and migratory potential via IL-6 secretion. Papaccio G, editor. PLoS One. 2016;11:e0166500. https://doi.org/10.1371/ journal.pone. 0166500 .

51. Heymann M-FF, Lézot F, Heymann D. The contribution of immune infiltrates and the local microenvironment in the pathogenesis of osteosarcoma. Cell Immunol. 2019;343:103711. https://doi.org/10.1016/j.cellimm.2017.10.011.

52. Mantovani A, Marchesi F, Malesci A, Laghi L, Allavena P. Tumour-associated macrophages as treatment targets in oncology. Nat Rev Clin Oncol. 2017;14:399-416. https://doi.org/10. 1038/nrclinonc.2016.217.

53. Murray PJ, Allen JE, Biswas SK, Fisher EA, Gilroy DW, Goerdt $\mathrm{S}$, et al. Macrophage activation and polarization: nomenclature and experimental guidelines. Immunity. 2014;41:14-20. https:// doi.org/10.1016/j.immuni.2014.06.008.

54. Buddingh EP, Kuijjer ML, Duim RAJ, Bürger H, Agelopoulos K, Myklebost $\mathrm{O}$, et al. Tumor-infiltrating macrophages are associated with metastasis suppression in high-grade osteosarcoma: a rationale for treatment with macrophage activating agents. Clin Cancer Res. 2011;17:2110-9. https://doi.org/10.1158/1078-0432. CCR-10-2047.

55. Koirala P, Roth ME, Gill J, Piperdi S, Chinai JM, Geller DS, et al. Immune infiltration and PD-L1 expression in the tumor microenvironment are prognostic in osteosarcoma. Sci Rep. 2016;6:1-10. https://doi.org/10.1038/srep30093.

56. Dumars C, Ngyuen J-M, Gaultier A, Lanel R, Corradini N, Gouin $\mathrm{F}$, et al. Dysregulation of macrophage polarization is associated with the metastatic process in osteosarcoma. Oncotarget. 2016;7:78343-54. https://doi.org/10.18632/oncotarget.13055.

57. Jia X, Feng G, Wang Z, Du Y, Shen C, Hui H, et al. Activation of mesenchymal stem cells by macrophages promotes tumor progression through immune suppressive effects. Oncotarget. 2016;7:20934-44. https://doi.org/10.18632/oncotarget.8064.

58. Liang X, Guo W, Ren T, Huang Y, Sun K, Zhang H, et al. Macrophages reduce the sensitivity of osteosarcoma to neoadjuvant chemotherapy drugs by secreting Interleukin- 1 beta. Cancer Lett. 2020;480:4-14. https://doi.org/10.1016/j.canlet.2020.03.019.

59. Sundara YT, Kostine M, Cleven AHG, Bovée JVMG, Schilham MW, Cleton-Jansen A-M. Increased PD-L1 and T-cell infiltration in the presence of HLA class I expression in metastatic highgrade osteosarcoma: a rationale for T-cell-based immunotherapy. Cancer Immunol Immunother. 2017;66:119-28. https://doi.org/ 10.1007/s00262-016-1925-3.

60. Gomez-Brouchet A, Illac C, Gilhodes J, Bouvier C, Aubert S, Guinebretiere J-M, et al. CD163-positive tumor-associated macrophages and CD8-positive cytotoxic lymphocytes are powerful diagnostic markers for the therapeutic stratification of osteosarcoma patients: An immunohistochemical analysis of the biopsies fromthe French OS2006 phase 3 t. Oncoimmunology. 2017;6:e1331193. https://doi.org/10.1080/2162402X.2017. 1331193.
61. De Palma M, Biziato D, Petrova TV. Microenvironmental regulation of tumour angiogenesis. Nat Rev Cancer. 2017;17:457-74. https://doi.org/10.1038/nrc.2017.51.

62. An R, Schmid R, Klausing A, Robering JW, Weber M, Bäuerle $\mathrm{T}$, et al. Proangiogenic effects of tumor cells on endothelial progenitor cells vary with tumor type in an in vitro and in vivo rat model. FASEB J. 2018;32:5587-601. https://doi.org/10.1096/fj. 201800135RR.

63. Ren K, Yao N, Wang G, Tian L, Ma J, Shi X, et al. Vasculogenic mimicry: a new prognostic sign of human osteosarcoma. Hum Pathol. 2014;45:2120-9. https://doi.org/10.1016/j.humpath.2014. 06.013 .

64. Kunz P, Fellenberg J, Moskovszky L, Sápi Z, Krenacs T, Machado I, et al. Improved survival in osteosarcoma patients with atypical low vascularization. Ann Surg Oncol. 2015;22:489-96. https://doi.org/10.1245/s10434-014-4001-2.

65. Chen D, Zhang Y-J, Zhu K, Wang W-C. A systematic review of vascular endothelial growth factor expression as a biomarker of prognosis in patients with osteosarcoma. Tumor Biol. 2013;34:1895-9. https://doi.org/10.1007/s13277-013-0733-z.

66. Takagi S, Takemoto A, Takami M, Oh-hara T, Fujita N. Platelets promote osteosarcoma cell growth through activation of the platelet-derived growth factor receptor-Akt signaling axis. Cancer Sci. 2014;105:983-8. https://doi.org/10.1111/cas.12464.

67. Cui J, Dean D, Hornicek FJ, Chen Z, Duan Z. The role of extracelluar matrix in osteosarcoma progression and metastasis. $\mathrm{J}$ Exp Clin Cancer Res. 2020;39:178. https://doi.org/10.1186/ s13046-020-01685-w.

68. Hirahata M, Osaki M, Kanda Y, Sugimoto Y, Yoshioka Y, Kosaka N, et al. PAI-1, a target gene of miR-143, regulates invasion and metastasis by upregulating MMP-13 expression of human osteosarcoma. Cancer Med. 2016;5:892-902. https://doi. org/10.1002/cam4.651.

69. Liu Y, Abulimiti N, Wang C. Collagen triple helix repeat containing 1 expression in osteosarcoma: a new predictor of prognosis. Ann Clin Lab Sci. 2018;48:338-44.

70. Shi K, Wang SL, Shen B, Yu FQ, Weng DF, Lin JH. Clinicopathological and prognostic values of fibronectin and integrin

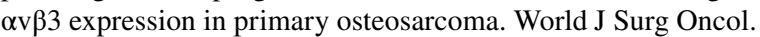
2019;17:1-12. https://doi.org/10.1186/s12957-019-1566-z.

71. Xu W, Li Z, Zhu X, Xu R, Xu Y. MiR-29 family inhibits resistance to methotrexate and promotes cell apoptosis by targeting COL3A1 and MCL1 in osteosarcoma. Med Sci Monit. 2018;24:8812-21. https://doi.org/10.12659/MSM.911972.

72. Luetke A, Meyers PA, Lewis I, Juergens H. Osteosarcoma treatment - where do we stand? A state of the art review. Cancer Treat Rev. 2014;40:523-32. https://doi.org/10.1016/j.ctrv.2013.11.006.

73. Fernandes I, Melo-Alvim C, Lopes-Brás R, Esperança-Martins M, Costa L. Osteosarcoma pathogenesis leads the way to new target treatments. Int J Mol Sci. 2021;22:813. https://doi.org/10. 3390/ijms22020813.

74. Chen Y, Di Grappa MA, Molyneux SD, McKee TD, Waterhouse $\mathrm{P}$, Penninger JM, et al. RANKL blockade prevents and treats aggressive osteosarcomas. Sci Transl Med. 2015;7:317ra197317ra197. https://doi.org/10.1126/scitranslmed.aad0295.

75. Boyce AM. Denosumab: an emerging therapy in pediatric bone disorders. Curr Osteoporos Rep. 2017;15:283-92. https://doi.org/ 10.1007/s11914-017-0380-1.

76. Bone HG, Wagman RB, Brandi ML, Brown JP, Chapurlat R, Cummings SR, et al. 10 years of denosumab treatment in postmenopausal women with osteoporosis: results from the phase 3 randomised FREEDOM trial and open-label extension. Lancet Diabetes Endocrinol. 2017;5:513-23. https://doi.org/10.1016/ S2213-8587(17)30138-9.

77. Punzo F, Tortora C, Argenziano M, Di Pinto D, Pota E, Di Martino M, et al. Can denosumab be used in combination with 
doxorubicin in osteosarcoma? Oncotarget. 2020;11:2763-73. https://doi.org/10.18632/oncotarget.27669.

78. Ohba T, Cates JMM, Cole HA, Slosky DA, Haro H, Ichikawa $\mathrm{J}$, et al. Pleiotropic effects of bisphosphonates on osteosarcoma. Bone. 2014;63:110-20. https://doi.org/10.1016/j.bone.2014.03. 005.

79. Ohba T, Cole HA, Cates JMM, Slosky DA, Haro H, Ando T, et al. Bisphosphonates inhibit osteosarcoma-mediated osteolysis via attenuation of tumor expression of MCP-1 and RANKL. J Bone Miner Res. 2014;29:1431-45. https://doi.org/10.1002/jbmr. 2182.

80. Goldsby RE, Fan TM, Villaluna D, Wagner LM, Isakoff MS, Meyer J, et al. Feasibility and dose discovery analysis of zoledronic acid with concurrent chemotherapy in the treatment of newly diagnosed metastatic osteosarcoma: a report from the Children's Oncology Group. Eur J Cancer. 2013;49:2384-91. https://doi.org/10.1016/j.ejca.2013.03.018.

81. Chou AJ, Kleinerman ES, Krailo MD, Chen Z, Betcher DL, Healey $\mathrm{JH}$, et al. Addition of muramyl tripeptide to chemotherapy for patients with newly diagnosed metastatic osteosarcoma. Cancer. 2009;115:5339-48. https://doi.org/10.1002/cncr.24566.

82. Punzo F, Bellini G, Tortora C, Di Pinto D, Argenziano M, Pota E, et al. Mifamurtide and TAM-like macrophages: effect on proliferation, migration and differentiation of osteosarcoma cells. Oncotarget. 2020;11:687-98. https://doi.org/10.18632/oncot arget.27479.

83. Meyers PA. Muramyl tripeptide-phosphatidyl ethanolamine encapsulated in liposomes (L-MTP-PE) in the treatment of osteosarcoma. Advances in Experimental Medicine and Biology. 2020 133-139. https://doi.org/10.1007/978-3-030-43032-0_11

84. Merchant MS, Wright M, Baird K, Wexler LH, RodriguezGalindo C, Bernstein D, et al. Phase I clinical trial of ipilimumab in pediatric patients with advanced solid tumors. Clin Cancer Res. 2016;22:1364-70. https://doi.org/10.1158/1078-0432. CCR-15-0491.

85. Tawbi HA, Burgess M, Bolejack V, Van Tine BA, Schuetze SM, $\mathrm{Hu}$ J, et al. Pembrolizumab in advanced soft-tissue sarcoma and bone sarcoma (SARC028): a multicentre, two-cohort, singlearm, open-label, phase 2 trial. Lancet Oncol. 2017;18:1493-501. https://doi.org/10.1016/S1470-2045(17)30624-1.

86. Tian Z, Niu X, Yao W. Receptor tyrosine kinases in osteosarcoma treatment: which is the key target? Front Oncol. 2020;10:1-13. https://doi.org/10.3389/fonc.2020.01642.

87. Navid F, Santana VM, Neel M, McCarville MB, Shulkin BL, $\mathrm{Wu} \mathrm{J}$, et al. A phase II trial evaluating the feasibility of adding bevacizumab to standard osteosarcoma therapy. Int J Cancer. 2017;141:1469-77. https://doi.org/10.1002/ijc.30841.

88. Pappo AS, Vassal G, Crowley JJ, Bolejack V, Hogendoorn PCW, Chugh R, et al. A phase 2 trial of R1507, a monoclonal antibody to the insulin-like growth factor-1 receptor (IGF-1R), in patients with recurrent or refractory rhabdomyosarcoma, osteosarcoma, synovial sarcoma, and other soft tissue sarcomas: Results of a Sarcoma Alliance. Cancer. 2014;120:2448-56. https://doi.org/ 10.1002/cncr.28728.

89. Italiano A, Mir O, Mathoulin-Pelissier S, Penel N, Piperno-Neumann S, Bompas E, et al. Cabozantinib in patients with advanced Ewing sarcoma or osteosarcoma (CABONE): a multicentre, single-arm, phase 2 trial. Lancet Oncol. 2020;21:446-55. https:// doi.org/10.1016/S1470-2045(19)30825-3.

90. Morrow JJ, Bayles I, Funnell APW, Miller TE, Saiakhova A, Lizardo MM, et al. Positively selected enhancer elements endow osteosarcoma cells with metastatic competence. Nat Med. 2018;24:176-85. https://doi.org/10.1038/nm.4475.

91. Koshkina NV, Khanna C, Mendoza A, Guan H, DeLauter L, Kleinerman ES. Fas-negative osteosarcoma tumor cells are selected during metastasis to the lungs: the role of the fas pathway in the metastatic process of osteosarcoma. Mol Cancer Res. 2007;5:991-9. https://doi.org/10.1158/1541-7786. MCR-07-0007.

92. Gross AC, Cam H, Phelps DA, Saraf AJ, Bid HK, Cam M, et al. IL-6 and CXCL8 mediate osteosarcoma-lung interactions critical to metastasis. JCI insight. 2018;3. https://doi.org/10. 1172/jci.insight.99791

93. Steeg PS. Targeting metastasis. Nat Rev Cancer. 2016;16:20118. https://doi.org/10.1038/nrc.2016.25.

94. Dowden H, Munro J. Trends in clinical success rates and therapeutic focus. Nat Rev Drug Discov. 2019;18:495-6. https://doi. org/10.1038/d41573-019-00074-z.

95. León IE, Cadavid-Vargas JF, Resasco A, Maschi F, Ayala MA, Carbone $\mathrm{C}$, et al. In vitro and in vivo antitumor effects of the VO-chrysin complex on a new three-dimensional osteosarcoma spheroids model and a xenograft tumor in mice. J Biol Inorg Chem. 2016;21:1009-20. https://doi.org/10.1007/ s00775-016-1397-0.

96. Guo X, Yu L, Zhang Z, Dai G, Gao T, Guo W. miR-335 negatively regulates osteosarcoma stem cell-like properties by targeting POU5F1. Cancer Cell Int. 2017;17:29. https://doi.org/10. 1186/s12935-017-0398-6.

97. Bai C, Yang M, Fan Z, Li S, Gao T, Fang Z. Associations of chemo- and radio-resistant phenotypes with the gap junction, adhesion and extracellular matrix in a three-dimensional culture model of soft sarcoma. J Exp Clin Cancer Res. 2015;34:1-10. https://doi.org/10.1186/s13046-015-0175-0.

98. Collier CD, Wirtz EC, Knafler GJ, Morris WZ, Getty PJ, Greenfield EM. Micrometastatic drug screening platform shows heterogeneous response to MAP chemotherapy in osteosarcoma cell lines. Clin Orthop Relat Res. 2018;476:1400-11. https://doi.org/ 10.1007/s11999.0000000000000059.

99. Oliveira MB, Neto AI, Correia CR, Rial-Hermida MI, AlvarezLorenzo C, Mano JF. Superhydrophobic chips for cell spheroids high-throughput generation and drug screening. ACS Appl Mater Interfaces. 2014;6:9488-95. https://doi.org/10.1021/am5018607.

100. Sarkar S, Peng CC, Tung YC. Comparison of VEGF-A secretion from tumor cells under cellular stresses in conventional monolayer culture and microfluidic three-dimensional spheroid models. PLoS One. 2020;15:1-21. https://doi.org/10.1371/journ al.pone. 0240833 .

101. Freeman FE, Burdis R, Mahon OR, Kelly DJ, Artzi N. A spheroid model of early and late-stage osteosarcoma mimicking the divergent relationship between tumor elimination and bone regeneration. Adv Healthc Mater. 2021;2101296:2101296. https://doi.org/ 10.1002/adhm.202101296.

102. Monteiro CF, Santos SC, Custódio CA, Mano JF. Human platelet lysates-based hydrogels: a novel personalized $3 \mathrm{~d}$ platform for spheroid invasion assessment. Adv Sci. 2020;7. https://doi.org/ 10.1002/advs.201902398

103. Monteiro CF, Custódio CA, Mano JF. Bioengineering a humanized 3D tri-culture osteosarcoma model to assess tumor invasiveness and therapy response. Acta Biomater. 2021. https://doi.org/ 10.1016/j.actbio.2021.07.034.

104. Jiang T, Xu G, Chen X, Huang X, Zhao J, Zheng L. Impact of hydrogel elasticity and adherence on osteosarcoma cells and osteoblasts. Adv Healthc Mater. 2019;8:1-11. https://doi.org/10. 1002/adhm.201801587.

105. Fallica B, Maffei JS, Villa S, Makin G, Zaman M. Alteration of cellular behavior and response to PI3K pathway inhibition by culture in 3D collagen gels. Munshi HG, editor. PLoS One. 2012;7:e48024. https://doi.org/10.1371/journal.pone.0048024.

106. Techavichit P, Gao Y, Kurenbekova L, Shuck R, Donehower LA, Yustein JT. Secreted frizzled-related protein 2 (sFRP2) promotes osteosarcoma invasion and metastatic potential. BMC Cancer. 2016;16:869. https://doi.org/10.1186/s12885-016-2909-6. 
107. Baranski Z, Booij TH, Kuijjer ML, de Jong Y, Cleton-Jansen A-M, Price LS, et al. MEK inhibition induces apoptosis in osteosarcoma cells with constitutive ERK1/2 phosphorylation. Genes Cancer. 2015;6:503-12. https://doi.org/10.18632/genesandca ncer.91.

108. Zuo Y, He X, Yang Y, Wei D, Sun J, Zhong M, et al. Microfluidic-based generation of functional microfibers for biomimetic complex tissue construction. Acta Biomater. 2016;38:153-62. https://doi.org/10.1016/j.actbio.2016.04.036.

109. Nishimura A, Akeda K, Matsubara T, Kusuzaki K, Matsumine A, Masuda K, et al. Transfection of NF-KB decoy oligodeoxynucleotide suppresses pulmonary metastasis by murine osteosarcoma. Cancer Gene Ther. 2011;18:250-9. https://doi.org/10.1038/cgt. 2010.75.

110. Yang F, Lu J, Ke Q, Peng X, Guo Y, Xie X. Magnetic mesoporous calcium sillicate/chitosan porous scaffolds for enhanced bone regeneration and photothermal-chemotherapy of osteosarcoma. Sci Rep. 2018;8:7345. https://doi.org/10.1038/ s41598-018-25595-2.

111. Bassi G, Panseri S, Dozio SM, Sandri M, Campodoni E, Dapporto $\mathrm{M}$, et al. Scaffold-based 3D cellular models mimicking the heterogeneity of osteosarcoma stem cell niche. Sci Rep. 2020;10:1-12. https://doi.org/10.1038/s41598-020-79448-y.

112. Palamà IE, Arcadio V, D'Amone S, Biasiucci M, Gigli G, Cortese B. Therapeutic PCL scaffold for reparation of resected osteosarcoma defect. Sci Rep. 2017;7:12672. https://doi.org/10.1038/ s41598-017-12824-3.

113. Riesco R, Boyer L, Blosse S, Lefebvre PM, Assemat P, Leichle $\mathrm{T}$, et al. Water-in-PDMS Emulsion templating of highly interconnected porous architectures for 3D cell culture. ACS Appl Mater Interfaces. 2019;11:28631-40. https://doi.org/10.1021/acsami. $9 \mathrm{~b} 07564$.

114. Tan PHS, Chia SS, Toh SL, Goh JCH, Nathan SS. The dominant role of IL-8 as an angiogenic driver in a three-dimensional physiological tumor construct for drug testing. Tissue Eng Part A. 2014;20:1758-66. https://doi.org/10.1089/ten.tea.2013.0245.

115. Rodrigues J, Heinrich MA, Teixeira LM, Prakash J. 3D In vitro model (R)evolution: unveiling tumor-stroma interactions. Trends in Cancer. 2021;7:249-64. https://doi.org/10.1016/j.trecan.2020. 10.009 .

116. Wegst UGK, Bai H, Saiz E, Tomsia AP, Ritchie RO. Bioinspired structural materials. Nat Mater. 2015;14:23-36. https://doi.org/ 10.1038/nmat4089.

117. González Díaz EC, Sinha S, Avedian RS, Yang F. Tissue-engineered 3D models for elucidating primary and metastatic bone cancer progression. Acta Biomater. 2019;99:18-32. https://doi. org/10.1016/j.actbio.2019.08.020.

118. Bose S, Roy M, Bandyopadhyay A. Recent advances in bone tissue engineering scaffolds. Trends Biotechnol. 2012;30:546-54. https://doi.org/10.1016/j.tibtech.2012.07.005.

119. Monteiro CF, Custódio CA, Mano JF. Three-dimensional osteosarcoma models for advancing drug discovery and development. Adv Ther. 2019;2:1800108. https://doi.org/10.1002/adtp.20180 0108 .

120. De Luca A, Raimondi L, Salamanna F, Carina V, Costa V, Bellavia $\mathrm{D}$, et al. Relevance of $3 \mathrm{~d}$ culture systems to study osteosarcoma environment. J Exp Clin Cancer Res. 2018;37:1-15. https://doi.org/10.1186/s13046-017-0663-5.

121. Stock K, Estrada MF, Vidic S, Gjerde K, Rudisch A, Santo VE, et al. Capturing tumor complexity in vitro: comparative analysis of 2D and 3D tumor models for drug discovery. Sci Rep. 2016;6:1-15. https://doi.org/10.1038/srep28951.

122. Pavlou M, Shah M, Gikas P, Briggs T, Roberts SJJ, Cheema U. Osteomimetic matrix components alter cell migration and drug response in a 3D tumour-engineered osteosarcoma model. Acta
Biomater. 2019;96:247-57. https://doi.org/10.1016/j.actbio. 2019.07.011.

123. Chen TY, Huang HC, Cao JL, Xin YJ, Luo WF, Ao NJ. Preparation and characterization of alginate/HACC/oyster shell powder biocomposite scaffolds for potential bone tissue engineering applications. RSC Adv. 2016;6:35577-88. https://doi.org/10. 1039/c5ra26805b.

124. Qin D, Wang N, You X-G, Zhang A-D, Chen X-G, Liu Y. Collagen-based biocomposites inspired by bone hierarchical structures for advanced bone regeneration: ongoing research and perspectives. Biomater Sci. 2022. https://doi.org/10.1039/D1BM0 $1294 \mathrm{~K}$.

125. Qasim M, Chae DS, Lee NY. Advancements and frontiers in nano-based 3D and 4D scaffolds for bone and cartilage tissue engineering. Int J Nanomedicine. 2019;14:4333-51. https://doi. org/10.2147/IJN.S209431.

126. Holzapfel BM, Wagner F, Loessner D, Holzapfel NP, Thibaudeau L, Crawford R, et al. Species-specific homing mechanisms of human prostate cancer metastasis in tissue engineered bone. Biomaterials. 2014;35:4108-15. https://doi.org/10.1016/j.bioma terials.2014.01.062.

127. Jabbari E, Sarvestani SK, Daneshian L, Moeinzadeh S. Optimum 3D matrix stiffness for maintenance of cancer stem cells is dependent on tissue origin of cancer cells. Engler AJ, editor. PLoS One. 2015;10:e0132377. https://doi.org/10.1371/journal. pone.0132377.

128. Sieh S, Lubik AA, Clements JA, Nelson CC, Hutmacher DW. Interactions between human osteoblasts and prostate cancer cells in a novel 3D in vitro model. Organogenesis. 2010;6:181-8. https://doi.org/10.4161/org.6.3.12041.

129. Liao J, Han R, Wu Y, Qian Z. Review of a new bone tumor therapy strategy based on bifunctional biomaterials. Bone Res. 2021;9:18. https://doi.org/10.1038/s41413-021-00139-z.

130. Ma H, He C, Cheng Y, Yang Z, Zang J, Liu J, et al. Localized codelivery of doxorubicin, cisplatin, and methotrexate by thermosensitive hydrogels for enhanced osteosarcoma treatment. ACS Appl Mater Interfaces. 2015;7:27040-8. https://doi.org/10.1021/ acsami.5b09112.

131. Rong ZJ, Yang LJ, Cai BT, Zhu LX, Cao YL, Wu GF, et al. Porous nano-hydroxyapatite/collagen scaffold containing drugloaded ADM-PLGA microspheres for bone cancer treatment. J Mater Sci Mater Med. 2016;27:1-12. https://doi.org/10.1007/ s10856-016-5699-0.

132. Monteiro MV, Gaspar VM, Ferreira LP, Mano JF. Hydrogel 3D: in vitro tumor models for screening cell aggregation mediated drug response. Biomater Sci. 2020;8:1855-64. https://doi.org/ 10.1039/c9bm02075f.

133. Nath S, Devi GR. Three-dimensional culture systems in cancer research: focus on tumor spheroid model. Pharmacol Ther. 2016;163:94-108. https://doi.org/10.1016/j.pharmthera.2016.03. 013.

134. Baek NH, Seo OW, Kim MS, Hulme J, An SSA. Monitoring the effects of doxorubicin on 3D-spheroid tumor cells in real-time. Onco Targets Ther. 2016;9:7207-18. https://doi.org/10.2147/ OTT.S112566.

135. Martins-Neves SR, Lopes ÁO, do Carmo A, Paiva AA, Simões PC, Abrunhosa AJ, et al. Therapeutic implications of an enriched cancer stem-like cell population in a human osteosarcoma cell line. BMC Cancer. 2012;12:139. https://doi.org/10.1186/ 1471-2407-12-139.

136. Chaddad H, Kuchler-Bopp S, Fuhrmann G, Gegout H, UbeaudSequier G, Schwinté P, et al. Combining 2D angiogenesis and 3D osteosarcoma microtissues to improve vascularization. Exp Cell Res. 2017;360:138-45. https://doi.org/10.1016/j.yexcr.2017.08. 035. 
137. Franchi-Mendes T, Eduardo R, Domenici G, Brito C. 3D cancer models: depicting cellular crosstalk within the tumour microenvironment. Cancers (Basel). 2021;13:4610. https://doi.org/10. 3390/cancers 13184610.

138. Bauleth-Ramos T, Feijão T, Gonçalves A, Shahbazi MA, Liu $\mathrm{Z}$, Barrias $\mathrm{C}$, et al. Colorectal cancer triple co-culture spheroid model to assess the biocompatibility and anticancer properties of polymeric nanoparticles. J Control Release. 2020;323:398-411. https://doi.org/10.1016/j.jconrel.2020.04.025.

139. Kuen J, Darowski D, Kluge T, Majety M. Pancreatic cancer cell/ fibroblast co-culture induces M2 like macrophages that influence therapeutic response in a 3D model. PLoS One. 2017;12:1-19. https://doi.org/10.1371/journal.pone.0182039.

140. Rebelo SP, Pinto C, Martins TR, Harrer N, Estrada MF, LozaAlvarez P, et al. 3D-3-culture: a tool to unveil macrophage plasticity in the tumour microenvironment. Biomaterials. 2018;163:185-97. https://doi.org/10.1016/j.biomaterials.2018. 02.030 .

141. Priwitaningrum DL, Blondé J-BG, Sridhar A, van Baarlen J, Hennink WE, Storm G, et al. Tumor stroma-containing 3D spheroid arrays: a tool to study nanoparticle penetration. J Control Release. 2016;244:257-68. https://doi.org/10.1016/j.jconrel. 2016.09.004.

142. Dutta D, Heo I, Clevers H. Disease modeling in stem cell-derived 3D organoid systems. Trends Mol Med. 2017;23:393-410. https://doi.org/10.1016/j.molmed.2017.02.007.

143. Driehuis E, Kretzschmar K, Clevers H. Establishment of patient-derived cancer organoids for drug-screening applications. Nat Protoc. 2020;15:3380-409. https://doi.org/10.1038/ s41596-020-0379-4.

144. He A, Huang Y, Cheng W, Zhang D, He W, Bai Y, et al. Organoid culture system for patient-derived lung metastatic osteosarcoma. Med Oncol. 2020;37:1-9. https://doi.org/10.1007/ s12032-020-01429-y.

145. Shemesh J, Jalilian I, Shi A, Heng Yeoh G, Knothe Tate ML, Ebrahimi WM. Flow-induced stress on adherent cells in microfluidic devices. Lab Chip. 2015;15:4114-27. https://doi.org/10. 1039/C5LC00633C.

146. Mitxelena-Iribarren O, Zabalo J, Arana S, Mujika M. Improved microfluidic platform for simultaneous multiple drug screening towards personalized treatment. Biosens Bioelectron. 2019;123:237-43. https://doi.org/10.1016/j.bios.2018.09.001.

147. Kim S, Kim W, Lim S, Jeon J. Vasculature-on-a-chip for in vitro disease models. Bioengineering. 2017;4:8. https://doi.org/10. 3390/bioengineering 4010008 .

148. Ruiz-Espigares J, Nieto D, Moroni L, Jiménez G, Marchal JA. Evolution of metastasis study models toward metastasis-on-achip: the ultimate model? Small. 2021;17. https://doi.org/10. 1002/smll.202006009

149. Huh D, Matthews BD, Mammoto A, Montoya-Zavala M, Yuan Hsin H, Ingber DE. Reconstituting organ-level lung functions on a chip. Science (80-). 2010;328:1662-8. https://doi.org/10.1126/ science. 1188302.

150. Hassell BA, Goyal G, Lee E, Sontheimer-Phelps A, Levy O, Chen CS, et al. Human organ chip models recapitulate orthotopic lung cancer growth, therapeutic responses, and tumor dormancy in vitro. Cell Rep. 2017;21:508-16. https://doi.org/10.1016/j. celrep.2017.09.043.

151. Weilbaecher KN, Guise TA, McCauley LK. Cancer to bone: a fatal attraction. Nat Rev Cancer. 2011;11:411-25. https://doi.org/ 10.1038/nrc3055

152. Mansoorifar A, Gordon R, Bergan RC, Bertassoni LE. Bone-ona-chip: microfluidic technologies and microphysiologic models of bone tissue. Adv Funct Mater. 2021;31:2006796. https://doi. org/10.1002/adfm.202006796.
153. Ahn J, Lim J, Jusoh N, Lee J, Park T-EE, Kim YT, et al. 3D Microfluidic bone tumor microenvironment comprised of hydroxyapatite/fibrin composite. Front Bioeng Biotechnol. 2019;7:1-13. https://doi.org/10.3389/fbioe.2019.00168.

154. Jeon JS, Bersini S, Gilardi M, Dubini G, Charest JL, Moretti M, et al. Human 3D vascularized organotypic microfluidic assays to study breast cancer cell extravasation. Proc Natl Acad Sci U S A. 2015;112:214-9. https://doi.org/10.1073/pnas.1417115112.

155. Bongio M, Lopa S, Gilardi M, Bersini S, Moretti M. A 3D vascularized bone remodeling model combining osteoblasts and osteoclasts in a CaP nanoparticle-enriched matrix. Nanomedicine. 2016;11:1073-91. https://doi.org/10.2217/nnm-2015-0021.

156. Ireson CR, Alavijeh MS, Palmer AM, Fowler ER, Jones HJ. The role of mouse tumour models in the discovery and development of anticancer drugs. Br J Cancer. 2019;121:101-8. https://doi. org/10.1038/s41416-019-0495-5.

157. Gengenbacher N, Singhal M, Augustin HG. Preclinical mouse solid tumour models: status quo, challenges and perspectives. Nat Rev Cancer. 2017;17:751-65. https://doi.org/10.1038/nrc.2017. 92.

158. LeBlanc AK, Mazcko CN. Improving human cancer therapy through the evaluation of pet dogs. Nat Rev Cancer. 2020;20:727-42. https://doi.org/10.1038/s41568-020-0297-3.

159. Entenberg D, Voiculescu S, Guo P, Borriello L, Wang Y, Karagiannis GS, et al. A permanent window for the murine lung enables high-resolution imaging of cancer metastasis. Nat Methods. 2018;15:73-80. https://doi.org/10.1038/nmeth.4511.

160. Lizardo MM, Sorensen PH. Practical considerations in studying metastatic lung colonization in osteosarcoma using the pulmonary metastasis assay. J Vis Exp. 2018. https://doi.org/10.3791/ 56332.

161. Lizardo MM, Morrow JJ, Miller TE, Hong ES, Ren L, Mendoza A, et al. Upregulation of glucose-regulated protein 78 in metastatic cancer cells is necessary for lung metastasis progression. Neoplasia. 2016;18:699-710. https://doi.org/10.1016/j.neo.2016. 09.001.

162. Ni BS, Tzao C, Huang JH. Plug-and-play in vitro metastasis system toward recapitulating the metastatic cascade. Sci Rep. 2019;9:1-13. https://doi.org/10.1038/s41598-019-54711-z.

163. Del Piccolo N, Shirure VS, Bi Y, Goedegebuure SP, Gholami S, Hughes CCW, et al. Tumor-on-chip modeling of organ-specific cancer and metastasis. Adv Drug Deliv Rev. 2021;175:113798. https://doi.org/10.1016/j.addr.2021.05.008.

164. Ko J, Ahn J, Kim S, Lee Y, Lee J, Park D, et al. Tumor spheroidon-a-chip: a standardized microfluidic culture platform for investigating tumor angiogenesis. Lab Chip. 2019;19:2822-33. https:// doi.org/10.1039/C9LC00140A.

165. Caballero D, Kaushik S, Correlo VM, Oliveira JM, Reis RL, Kundu SC. Organ-on-chip models of cancer metastasis for future personalized medicine: from chip to the patient. Biomaterials. 2017;149:98-115. https://doi.org/10.1016/j.biomaterials.2017. 10.005 .

166. Aleman J, Skardal A. A multi-site metastasis-on-a-chip microphysiological system for assessing metastatic preference of cancer cells. Biotechnol Bioeng. 2019;116:936-44. https://doi.org/ 10.1002/bit.26871.

167. Skardal A, Murphy SV, Devarasetty M, Mead I, Kang HW, Seol YJ, et al. Multi-tissue interactions in an integrated three-tissue organ-on-a-chip platform. Sci Rep. 2017;7:1-16. https://doi.org/ 10.1038/s41598-017-08879-x.

168. Datta P, Ayan B, Ozbolat IT. Bioprinting for vascular and vascularized tissue biofabrication. Acta Biomater. 2017;51:1-20. https://doi.org/10.1016/j.actbio.2017.01.035.

169. Wang YI, Shuler ML. UniChip enables long-term recirculating unidirectional perfusion with gravity-driven flow for 
microphysiological systems. Lab Chip. 2018;18:2563-74. https:// doi.org/10.1039/c81c00394g.

170. Van Duinen V, Van Den Heuvel A, Trietsch SJ, Lanz HL, Van Gils JM, Van Zonneveld AJ, et al. 96 perfusable blood vessels to study vascular permeability in vitro. Sci Rep. 2017;7:1-11. https://doi.org/10.1038/s41598-017-14716-y.

171. Vis MAM, Ito K, Hofmann S. Impact of culture medium on cellular interactions in in vitro co-culture systems. Front Bioeng Biotechnol. 2020;8:1-8. https://doi.org/10.3389/fbioe.2020. 00911.

172. Sasaki H, Enomoto J, Ikeda Y, Honda H, Fukuda J, Kato R. Comparisons of cell culture medium using distribution of morphological features in microdevice. J Biosci Bioeng. 2016;121:117-23. https://doi.org/10.1016/j.jbiosc.2015.05.011.

173. Low LA, Mummery C, Berridge BR, Austin CP, Tagle DA. Organs-on-chips: into the next decade. Nat Rev Drug Discov. 2020. https://doi.org/10.1038/s41573-020-0079-3.

174. Mohseny AB, MacHado I, Cai Y, Schaefer KL, Serra M, Hogendoorn PCW, et al. Functional characterization of osteosarcoma cell lines provides representative models to study the human disease. Lab Investig. 2011;91:1195-205. https://doi.org/10.1038/ labinvest.2011.72.

175. Bray LJ, Hutmacher DW, Bock N. Addressing patient specificity in the engineering of tumor models. Front Bioeng Biotechnol. 2019;7:1-36. https://doi.org/10.3389/fbioe.2019.00217.

176. Bar-Ephraim YE, Kretzschmar K, Clevers H. Organoids in immunological research. Nat Rev Immunol. 2020;20:279-93. https://doi.org/10.1038/s41577-019-0248-y.

177. Bauman E, Feijão T, Carvalho DTO, Granja PL, Barrias CC. Xeno-free pre-vascularized spheroids for therapeutic applications. Sci Rep. 2018;8:1-13. https://doi.org/10.1038/ s41598-017-18431-6.

178. Carvalho MR, Lima D, Reis RL, Correlo VM, Oliveira JM. Evaluating biomaterial- and microfluidic-based 3D tumor models. Trends Biotechnol. 2015;33:667-78. https://doi.org/10.1016/j. tibtech.2015.09.009.

179. Moroni L, Burdick JA, Highley C, Lee SJ, Morimoto Y, Takeuchi $\mathrm{S}$, et al. Biofabrication strategies for 3D in vitro models and regenerative medicine. Nat Rev Mater. 2018;3:21-37. https:// doi.org/10.1038/s41578-018-0006-y.
180. Datta P, Dey M, Ataie Z, Unutmaz D, Ozbolat IT. 3D bioprinting for reconstituting the cancer microenvironment. npj Precis Oncol. 2020;4:18. https://doi.org/10.1038/s41698-020-0121-2.

181. Fischetti T, Di Pompo G, Baldini N, Avnet S, Graziani G. 3D Printing and bioprinting to model bone cancer: the role of materials and nanoscale cues in directing cell behavior. Cancers (Basel). 2021;13:4065. https://doi.org/10.3390/cancers131 64065.

182. Langer EM, Allen-Petersen BL, King SM, Kendsersky ND, Turnidge MA, Kuziel GM, et al. Modeling tumor phenotypes in vitro with three-dimensional bioprinting. Cell Rep. 2019;26:608-23. https://doi.org/10.1016/j.celrep.2018.12.090.

183. Wang X, Tolba E, Schröder HC, Neufurth M, Feng Q, Diehl-Seifert $\mathrm{B}$, et al. Effect of bioglass on growth and biomineralization of SaOS-2 cells in hydrogel after 3D Cell bioprinting. Malaval L, editor. PLoS One. 2014;9:e112497. https://doi.org/10.1371/ journal.pone.0112497.

184. Neufurth M, Wang X, Schröder HC, Feng Q, Diehl-Seifert B, Ziebart T, et al. Engineering a morphogenetically active hydrogel for bioprinting of bioartificial tissue derived from human osteoblast-like SaOS-2 cells. Biomaterials. 2014;35:8810-9. https://doi.org/10.1016/j.biomaterials.2014.07.002.

185. Cui H, Esworthy T, Zhou X, Hann SY, Glazer RI, Li R, et al. Engineering a novel 3D printed vascularized tissue model for investigating breast cancer metastasis to bone. Adv Healthc Mater. 2020;9:1900924. https://doi.org/10.1002/adhm.20190 0924.

186. Pouliot N, Pearson HB BA. Investigating metastasis using in vitro platforms. In: In: Madame Curie Bioscience Database [Internet]. Austin (TX): Landes Bioscience; 2000-2013. Available from: https://www.ncbi.nlm.nih.gov/books/NBK100379/.

187. Zhang B, Radisic M. Organ-on-a-chip devices advance to market. Lab Chip. 2017;17:2395-420. https://doi.org/10.1039/C6LC0 1554A.

Publisher's Note Springer Nature remains neutral with regard to jurisdictional claims in published maps and institutional affiliations. 